\title{
Undrained anisotropy and rotational shear in granular soil
}

\author{
Z. X. YANG*, X. S. LI† and J. YANG*
}

\begin{abstract}
The impact of fabric anisotropy on the behaviour of granular soil remains a subject of great interest. In particular, the effects of principal stress rotation on the undrained response of saturated sand are not fully understood. This paper describes an experimental investigation conducted in an automated hollow cylinder apparatus into the undrained anisotropic behaviour of saturated sand in rotational shear, which is defined as a class of non-proportional loading with a continuous rotation of the principal stress directions but a constant deviatoric stress. Special attention in this investigation was placed on the influence of the relative magnitude of the intermediate principal stress, characterised by the parameter $b=\left(\sigma_{2}-\sigma_{3}\right) /\left(\sigma_{1}-\sigma_{3}\right)$, on the pore pressure response and deformation characteristics. The experimental observations indicate that soil specimens, even in very dense state, were weakened by the build-up of pore water pressure in rotational shear. The intermediate principal stress parameter $b$ was not a negligible factor for the behaviour of saturated sand in the rotation shear, but had significant impact. Under otherwise identical conditions, the soil specimen rotationally sheared under the condition $b=0$ exhibited a much stronger resistance to pore pressure build-up and a less dramatic stiffness degradation than that sheared under the condition $b=$ 1.0. This observation is considered to be directly associated with the soil fabric anisotropy.
\end{abstract}

KEYWORDS: anisotropy; deformation; fabric/structure of soils; laboratory tests; sands
L'influence de l'anisotropie de fabrique sur le comportement des sols granulaires reste un sujet soulevant un grand intérêt. Plus particulièrement, les effets de rotation des contraintes principales sur la réponse non drainée de sable saturé ne sont pas parfaitement compris. Cet article décrit une étude expérimentale réalisée dans un appareil à cylindre creux automatisé, visant à observer le comportement anisotrope non drainé de sable saturé pour un cisaillement en rotation, ce qui est défini comme une classe de charge non proportionnelle avec une rotation continue des directions de contraintes principales mais une contrainte déviatorique constante. On s'intéresse tout particulièrement à l'influence de l'amplitude relative de la contrainte principale intermédiaire, dont les effets sont commodément observés par le biais du paramètre $b\left(\sigma_{2}-\sigma_{3}\right)=\left(\sigma_{1}-\sigma_{3}\right)$, sur la réponse de pression interstitielle et les caractéristiques de déformation. Les observations expérimentales indiquent que les échantillons de sol, même dans un état à forte densité, sont affaiblis par l'accumulation de pression hydrique interstitielle pour le cisaillement en rotation. Le paramètre $b$ de la contrainte principale intermédiaire est apparu comme un facteur non négligeable pour le comportement du sable saturé sous cisaillement en rotation, avec un impact significatif. Toute autre condition étant identique, l'échantillon de sol soumis au cisaillement en rotation avec $b=0$ offre une bien plus grande résistance à l'augmentation de pression interstitielle et présente une dégradation de la rigidité moins importante que les spécimens soumis à $b=1,0$. Cette observation est estimée être en lien direct avec l'anisotropie de fabrique du sol.

\section{INTRODUCTION}

In general, granular soil is inherently anisotropic because of particle orientation in the deposition process. This inherent anisotropy highlights the fact that the response of a granular soil to loading will depend on the orientation of principal stresses with reference to the depositional plane. Additional anisotropy in the soil may be induced by stress changes in both magnitude and direction. The impact of anisotropy on the behaviour of sand has long been recognised (Arthur \& Menzies, 1972; Oda, 1972). In recent years serious effort has been made to examine the anisotropy of saturated sand in undrained conditions (e.g. Ishihara, 1993; Vaid \& Sivathayalan, 1996; Riemer \& Seed, 1997; Yoshimine \& Ishihara, 1998). The aim was to clarify uncertainties in the determination of the steady-state strength and flow liquefaction potential, which are of vital importance in the analysis of flow failure of a granular soil mass (Finn, 2000; Yang, 2002). It has been found that, under otherwise identical conditions, the shearing mode has great influence on the undrained response of sand. While sand may fail along a

Manuscript received 4 April 2006; revised manuscript accepted 25 January 2007.

Discussion on this paper closes on 1 October 2007, for further details see p. ii.

* Department of Civil Engineering, The University of Hong Kong.

$\dagger$ Department of Civil Engineering, Hong Kong University of Science and Technology. dilative stress path in triaxial compression, it may also fail along a contractive stress path in triaxial extension. In other words, the undrained shear behaviour is more contractive and softer in triaxial extension than in triaxial compression. This difference is considered directly related to the fabric anisotropy of the soil. Indeed, by using torsional shear tests, it has been shown that the undrained response of sand can be significantly affected by the direction of principal stresses in reference to the orientation of the soil specimen (Nakata et al., 1998; Yoshimine et al., 1998).

Most investigations into the undrained anisotropy of granular soil appear to have focused on cases where the major principal stress direction was fixed at an orientation to the axis of the symmetry of the soil specimen during shear. However, many field loading situations, such as wave loading on seabed deposits, multidirectional earthquake loading in level ground, and lateral cyclic loading on the soil behind retaining structures, involve rotation of the principal stress directions during shear. The stress paths associated with these loading situations may be classified as non-proportional loading ( $\mathrm{Li} \&$ Dafalias, 2004), as compared with conventional proportional loading in which the deviatoric stress components are kept in constant ratio to each other (Budiansky, 1959). Evidently conventional triaxial compression and extension are typical cases of proportional loading.

Using cyclic triaxial-torsional shear tests, Ishihara \& Towhata (1983) were among the first to seriously examine the effects of rotation of the principal stress directions on 
the undrained response of saturated sand. The test apparatus allowed torsional shear stress to be applied independent of vertical and horizontal stresses to a soil specimen. The specimen was a hollow cylinder measuring $100 \mathrm{~mm}$ in outer diameter, $60 \mathrm{~mm}$ in inner diameter and $104 \mathrm{~mm}$ in length. A significant finding was that, even when the amplitude of the combined shear stress was kept constant during shear, rotation of principal stresses was able to generate pore water pressure and subsequently reduce the strength of the sand.

As noted by Shibuya et al. (1984), the hollow cylinder apparatus used by Ishihara \& Towhata (1983) suffered from limitations in that the inner and outer pressures could not be independently controlled. The limitations resulted in the ratio between principal stresses, measured by $b=\left(\sigma_{2}-\sigma_{3}\right) /$ $\left(\sigma_{1}-\sigma_{3}\right)$, and the mean total stress, measured by $p=$ $\left(\sigma_{1}+\sigma_{2}+\sigma_{3}\right) / 3$, changing cyclically during loading. Rotation of the principal stress directions while maintaining conditions of constant $b$ and $p$ was successfully achieved by Symes et al. (1984) for a medium loose sand. In their tests $b$ was held at 0.5 while the major principal stress was rotated from $\alpha=0^{\circ}$ to $\alpha=45^{\circ}$, where $\alpha$ denotes the orientation of the major principal stress relative to the vertical direction of the sample in torsional shear tests (Fig. 1). More recently, Nakata et al. (1998) experimentally investigated the undrained response of saturated sand at various densities subjected to rotation of the principal stress directions. Similarly, all tests were conducted at the condition $b=0 \cdot 5$, using a hollow cylinder apparatus that accommodated specimens $100 \mathrm{~mm}$ in outer diameter, $60 \mathrm{~mm}$ in inner diameter and $200 \mathrm{~mm}$ long.

Recalling the significant impact caused by the shear mode in proportional loading on the undrained behaviour of sand, one may be aware of the underlying influence of the intermediate principal stress. This is because in conventional triaxial compression $b=0$, whereas in triaxial extension $b$ $=1 \cdot 0$. In view of this fact, great concern has arisen over the influence of the intermediate principal stress in non-proportional loading conditions in which rotation of principal stresses is involved. As a first step towards addressing this subject, this paper describes a series of undrained tests that were carried out on saturated sand using an automated hollow cylinder apparatus. The emphasis of this paper is placed on the influence of the intermediate principal stress, characterised by different $b$ values, in rotational shear. The rotational shear is herein defined as a class of non-proportional loading in which the second invariant of the deviatoric stress, $J_{2 \mathrm{D}}$, remains constant while the principal stress directions are continuously rotated relative to the soil specimen. In addition to the effects of the intermediate principal stress, this paper will also examine the effects of the relative density of sand and the shear stress magnitude in undrained

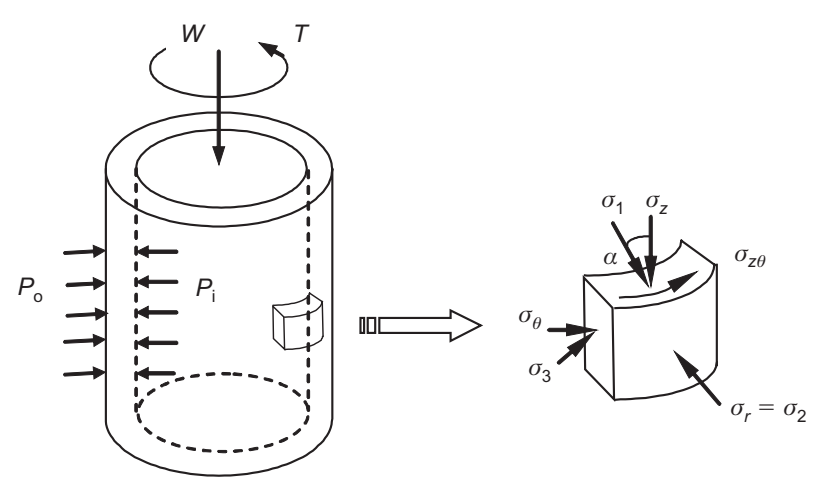

Fig. 1. Stress state in hollow cylinder torsional shear rotational shear as well as the relations between these effects.

\section{EQUIPMENT AND TEST SCHEME \\ Hollow cylinder apparatus}

In order to investigate the behaviour of soil under different principal stress directions or magnitudes, it is necessary to apply shear stress as well as normal stress to the surface of a specimen in an independently controlled manner. In the laboratory, the torsional shear test, in which a hollow cylindrical specimen is confined between two membrane sheets, offers the means to apply the normal stresses individually to a specimen, including vertical normal stress, inner and outer cell pressures as well as the shear stress (see Fig. 1). By combining the normal stresses and shear stress, complicated loading conditions can be simulated. A newly developed torsional shear device, which can accommodate a specimen of large dimensions and has a closed-loop control system, was used in the tests.

The device has four subsystems responsible for the control of the axial load $(W)$, torque $(T)$, inner cell pressure $\left(P_{\mathrm{i}}\right)$ and outer cell pressure $\left(P_{\mathrm{o}}\right)$ respectively. The axial/vertical load is generated by the magnetic field coils with electric currents and monitored by an axial load cell mounted on the loading shaft. The torque is applied by a servo-actuator located beneath the coils and recorded by another load cell measuring the torque magnitude. The corresponding rotating angle can be recorded accordingly when the servo-actuator is in the position control mode. A pneumatic loading unit is responsible for regulating the inner and outer cell pressures, which are recorded by pressure transducers. The effective stress is monitored by a differential transducer, such that the pore pressure can be calculated. The axial/vertical displacement is measured by two LVDTs, which are attached to the top cap of the hollow specimen. The volume changes of the specimen (for drained conditions) and the inner chamber (filled with de-aired water) are measured separately by burette-type measuring devices. The changes in the inner and outer radii can be calculated from the axial deformation and the volume changes of the specimen and the inner chamber, by assuming that the deformation is small such that the specimen remains cylindrical.

The hollow cylinder apparatus can accommodate specimens having the following dimensions: outer diameter $D_{\mathrm{o}}=$ $200 \mathrm{~mm}$, inner diameter $D_{\mathrm{i}}=150 \mathrm{~mm}$, and height $H=$ $314 \mathrm{~mm}$. As the frictional end platens constrain the radial deformation of the specimen near the end zones, specimens of greater height have an advantage in that a relatively uniform deformation zone can be developed at the middle part of the specimen.

\section{Sample preparation method}

The tests were conducted on Toyoura sand, a widely used standard sand consisting of subrounded to subangular particles. The physical properties of the sand used in this study are given in Table 1. The dry deposition method was employed in the sample preparation. Oven-dried sand was weighed and poured into the hollow space between two moulds with a spoon and a funnel. It was attempted to keep zero falling head and then tap the outer mould gently using a rubber mallet to adjust the density of the sample, layer by layer. The sand was deposited slightly above the top of the moulds to avoid partial contact between the soil particles and the loading cap, and then the loading cap was put on the top of the specimen with a small pressure. After filling the inner cell and outer chamber with de-aired water, the saturation process was carried out under a differential 
Table 1. Physical properties of Toyoura sand used in tests

\begin{tabular}{l|c|c|c|c}
\hline $\begin{array}{l}\text { Mean diameter } \\
D_{50}: \mathrm{mm}\end{array}$ & $\begin{array}{c}\text { Uniformity } \\
\text { coefficient, } U_{\mathrm{c}}\end{array}$ & $\begin{array}{c}\text { Maximum void } \\
\text { ratio, } e_{\max }\end{array}$ & $\begin{array}{c}\text { Minimum void } \\
\text { ratio, } e_{\min }\end{array}$ & $\begin{array}{c}\text { Specific } \\
\text { gravity, } G_{\mathrm{s}}\end{array}$ \\
\hline 0.23 & 1.32 & 0.977 & 0.597 & 2.65 \\
\hline
\end{tabular}
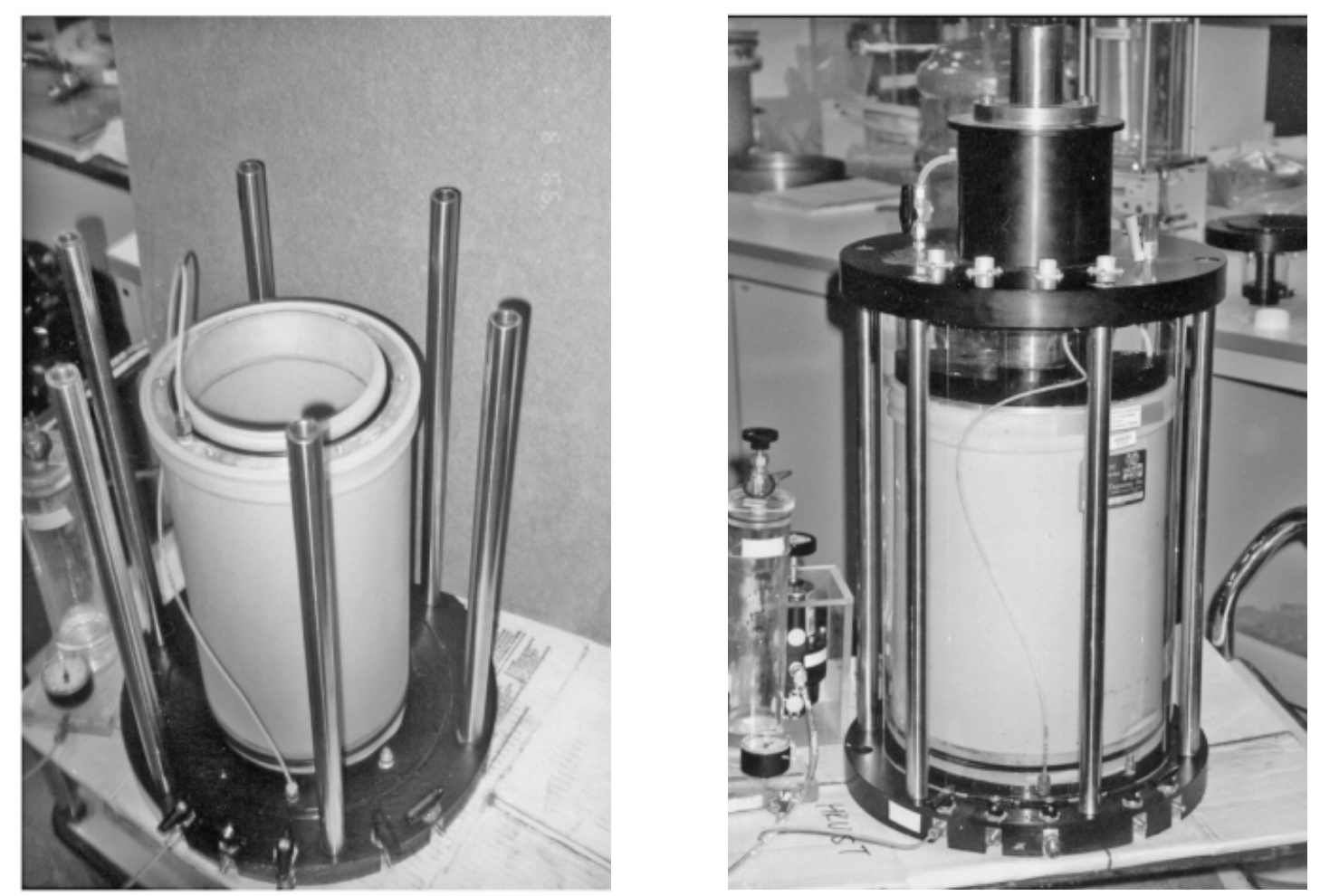

Fig. 2. Set-up of a hollow cylindrical sample

Table 2. Equations for data interpretation

\begin{tabular}{|c|c|c|}
\hline & Stress & Strain \\
\hline Vertical & $\sigma_{z}=\frac{W}{\pi\left(r_{\mathrm{o}}^{2}-r_{\mathrm{i}}^{2}\right)}+\frac{P_{\mathrm{o}}\left(r_{\mathrm{o}}^{2}-r_{\mathrm{d}}^{2}\right)-P_{\mathrm{i}} r_{\mathrm{i}}^{2}}{r_{\mathrm{o}}^{2}-r_{\mathrm{i}}^{2}}$ & $\varepsilon_{z}=\frac{z}{H}$ \\
\hline Radial & $\sigma_{\mathrm{r}}=\frac{P_{\mathrm{o}} r_{\mathrm{o}}+P_{\mathrm{i}} r_{\mathrm{i}}}{r_{\mathrm{o}}+r_{\mathrm{i}}}$ & $\varepsilon_{\mathrm{r}}=-\frac{u_{\mathrm{o}}-u_{\mathrm{i}}}{r_{\mathrm{o}}-r_{\mathrm{i}}}$ \\
\hline Circumferential & $\sigma_{\theta}=\frac{P_{\mathrm{o}} r_{\mathrm{o}}-P_{\mathrm{i}} r_{\mathrm{i}}}{r_{\mathrm{o}}-r_{\mathrm{i}}}$ & $\varepsilon_{\theta}=-\frac{u_{\mathrm{o}}+u_{\mathrm{i}}}{r_{\mathrm{o}}+r_{\mathrm{i}}}$ \\
\hline Shear & $\sigma_{z \theta}=\frac{1}{2}\left[\frac{3 T}{2 \pi\left(r_{\mathrm{o}}^{3}-r_{\mathrm{i}}^{3}\right)}+\frac{4\left(r_{\mathrm{o}}^{3}-r_{\mathrm{i}}^{3}\right) T}{3 \pi\left(r_{\mathrm{o}}^{2}-r_{\mathrm{i}}^{2}\right)\left(r_{\mathrm{o}}^{4}-r_{\mathrm{i}}^{4}\right)}\right]$ & $\varepsilon_{z \theta}=\frac{\theta\left(r_{\mathrm{o}}^{3}-r_{\mathrm{i}}^{3}\right)}{3 H\left(r_{\mathrm{o}}^{2}-r_{\mathrm{i}}^{2}\right)}$ \\
\hline Major principal & $\sigma_{1}=\frac{\sigma_{z}+\sigma_{\theta}}{2}+\sqrt{\left(\frac{\sigma_{z}-\sigma_{\theta}}{2}\right)^{2}+\sigma_{z \theta}^{2}}$ & $\varepsilon_{1}=\frac{\varepsilon_{z}+\varepsilon_{\theta}}{2}+\sqrt{\left(\frac{\varepsilon_{z}-\varepsilon_{\theta}}{2}\right)^{2}+\varepsilon_{z \theta}^{2}}$ \\
\hline Intermediate principal & $\sigma_{2}=\sigma_{r}$ & $\varepsilon_{2}=\varepsilon_{r}$ \\
\hline Minor principal & $\sigma_{3}=\frac{\sigma_{z}+\sigma_{\theta}}{2}-\sqrt{\left(\frac{\sigma_{z}-\sigma_{\theta}}{2}\right)^{2}+\sigma_{z \theta}^{2}}$ & $\varepsilon_{3}=\frac{\varepsilon_{z}+\varepsilon_{\theta}}{2}-\sqrt{\left(\frac{\varepsilon_{z}-\varepsilon_{\theta}}{2}\right)^{2}+\varepsilon_{z \theta}^{2}}$ \\
\hline Volumetric & $p^{\prime}=\frac{\sigma_{1}^{\prime}+\sigma_{2}^{\prime}+\sigma_{3}^{\prime}}{3}=\frac{\sigma_{1}+\sigma_{2}+\sigma_{3}}{3}-u$ & $\varepsilon_{\mathrm{v}}=\varepsilon_{1}+\varepsilon_{2}+\varepsilon_{3}$ \\
\hline Deviatoric & $q=\sqrt{\frac{1}{2}\left[\left(\sigma_{1}-\sigma_{2}\right)^{2}+\left(\sigma_{2}-\sigma_{3}\right)^{2}+\left(\sigma_{3}-\sigma_{1}\right)^{2}\right]}$ & $\varepsilon_{q}=\sqrt{\frac{2}{9}\left[\left(\varepsilon_{1}-\varepsilon_{2}\right)^{2}+\left(\varepsilon_{2}-\varepsilon_{3}\right)^{2}+\left(\varepsilon_{3}-\varepsilon_{1}\right)^{2}\right]}$ \\
\hline
\end{tabular}


vacuum pressure of $30 \mathrm{kPa}$; this procedure normally lasted about $6 \mathrm{~h}$. Photographs of a specimen after preparation are shown in Fig. 2.

\section{Data interpretation}

The equations used for calculation of stress and strain components in torsional shear tests, which are based mainly on the studies of Hight et al. (1983) and Miura et al. (1986), are summarised in Table 2. All the stress components except the vertical stress, which is obtained based on the equilibrium condition, are dependent on the thin-wall assumption. Here, the derivations of the stress components $\sigma_{\theta}, \sigma_{r}$ and $\sigma_{z \theta}$ are briefly described.

Considering the equilibrium of the wall subjected to both inner and outer pressures, elementary mechanics shows that both the radial stress $\sigma_{r}$ and the circumferential stress $\sigma_{\theta}$ vary with the location $r$, and they can be expressed as

$$
\sigma_{r}=\frac{P_{\mathrm{o}} r_{\mathrm{o}}^{2}}{r_{\mathrm{o}}^{2}-r_{\mathrm{i}}^{2}}\left(1-\frac{r_{\mathrm{i}}^{2}}{r^{2}}\right)-\frac{P_{\mathrm{i}} r_{\mathrm{i}}^{2}}{r_{\mathrm{o}}^{2}-r_{\mathrm{i}}^{2}}\left(1-\frac{r_{\mathrm{o}}^{2}}{r^{2}}\right)
$$

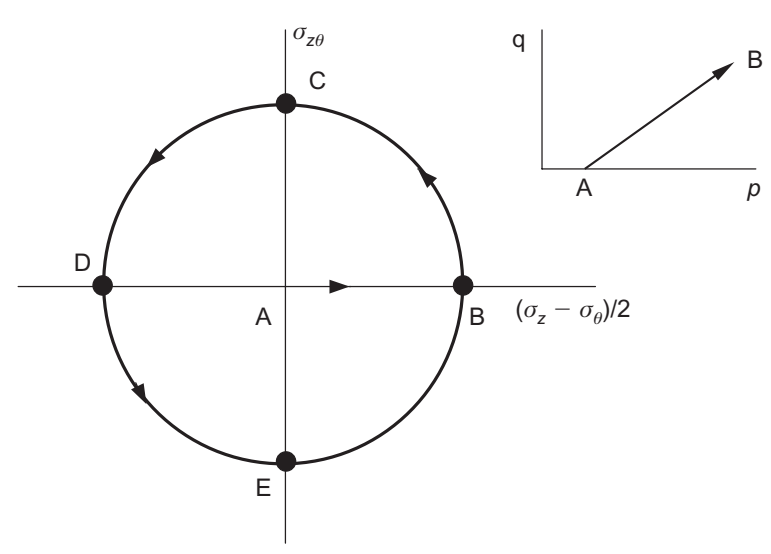

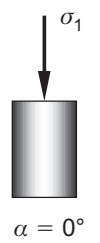

State B

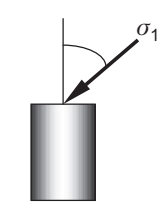

$\alpha=45^{\circ}$

State C

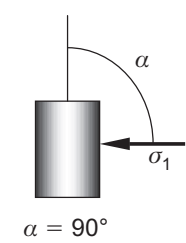

State D

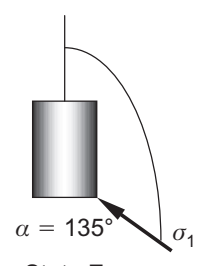

State $\mathrm{E}$
Fig. 3. Stress path in deviatoric stress space

$$
\sigma_{\theta}=\frac{P_{\mathrm{o}} r_{\mathrm{o}}^{2}}{r_{\mathrm{o}}^{2}-r_{\mathrm{i}}^{2}}\left(1+\frac{r_{\mathrm{i}}^{2}}{r^{2}}\right)-\frac{P_{\mathrm{i}} r_{\mathrm{i}}^{2}}{r_{\mathrm{o}}^{2}-r_{\mathrm{i}}^{2}}\left(1+\frac{r_{\mathrm{o}}^{2}}{r^{2}}\right)
$$

where $r_{\mathrm{o}}$ and $r_{\mathrm{i}}$ are the outer and inner radii respectively. By averaging the stress components without weighting for $r$, that is, $\int_{r_{\mathrm{i}}}^{r_{\mathrm{o}}} \sigma_{\mathrm{r}} \mathrm{d} r / \int_{r_{\mathrm{i}}}^{r_{\mathrm{o}}} \mathrm{d} r$ and $\int_{r_{\mathrm{i}}}^{r_{\mathrm{o}}} \sigma_{\theta} \mathrm{d} r / \int_{r_{\mathrm{i}}}^{r_{\mathrm{o}}} \mathrm{d} r$, one may obtain the representative stress expressions, as shown in Table 2. There is another way to average the stress components, which is conducted over the volume of the specimen (Vaid et al.,

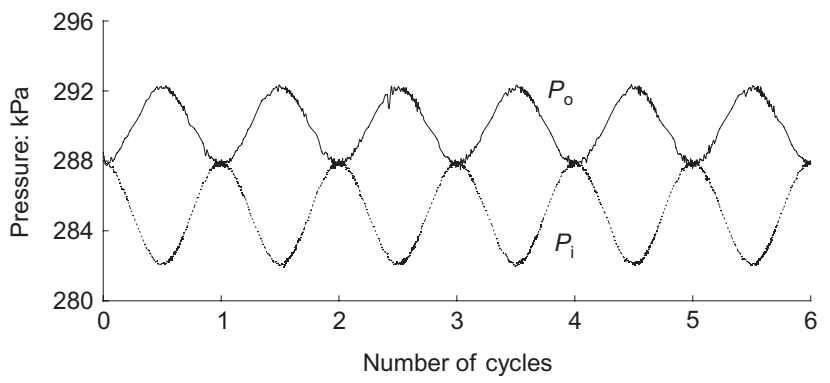

(a)

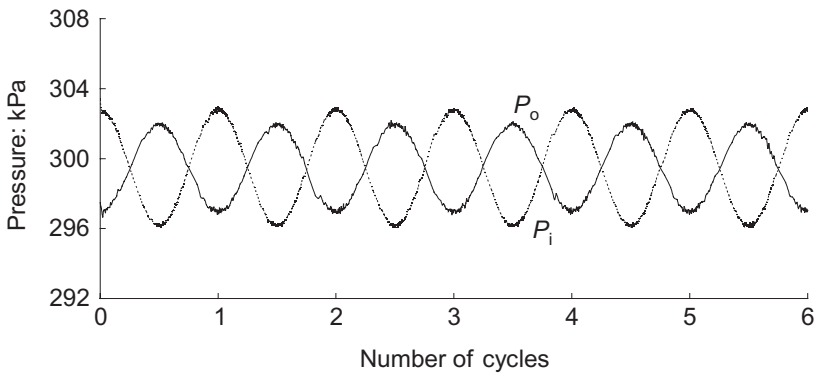

(b)

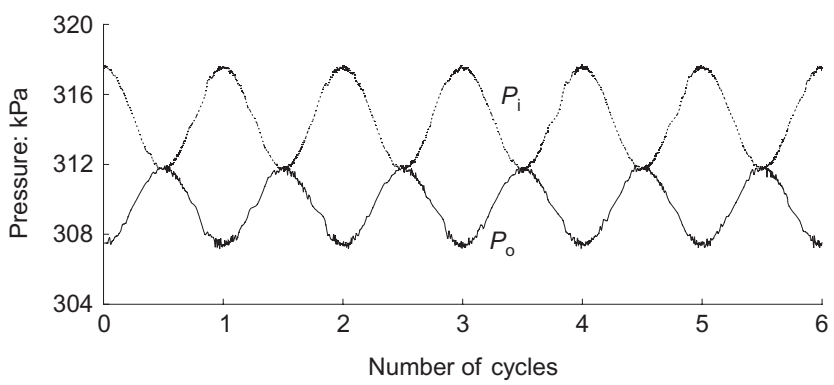

(c)

Fig. 4. Variation of outer and inner cell pressures in rotational shear: (a) $b=0$; (b) $b=0.5$; (c) $b=1 \cdot 0$

\begin{tabular}{|c|c|c|c|c|c|}
\hline \multicolumn{2}{|l|}{ Test ID } & \multirow{3}{*}{$\begin{array}{c}\begin{array}{c}\text { Initial void ratio } e_{\mathrm{o}} \\
\text { (after consolidation) }\end{array} \\
0.707 \\
0.707\end{array}$} & \multirow{2}{*}{$\begin{array}{c}\text { Relative density, } \\
D_{r}: \% \\
\sim 70\end{array}$} & \multirow{2}{*}{$\begin{array}{c}\text { Deviatoric stress, } \\
q: \mathrm{kPa}\end{array}$} & \multirow{2}{*}{$\begin{array}{l}\text { Intermediate principal } \\
\text { stress parameter } b \\
0\end{array}$} \\
\hline Series I & RCD70-2 & & & & \\
\hline & RSD70-2 & & $\sim 70$ & 34.65 & $0 \cdot 5$ \\
\hline & RED70-2 & $0 \cdot 711$ & $\sim 70$ & $34 \cdot 65$ & $1 \cdot 0$ \\
\hline \multirow[t]{3}{*}{ Series II } & RCD70-3 & $0 \cdot 699$ & $\sim 70$ & 51.96 & 0 \\
\hline & RSD70-3 & $0 \cdot 703$ & $\sim 70$ & $51 \cdot 96$ & $0 \cdot 5$ \\
\hline & RED70-3 & 0.699 & $\sim 70$ & $51 \cdot 96$ & $1 \cdot 0$ \\
\hline \multirow[t]{3}{*}{ Series III } & RCD90-2 & $0 \cdot 638$ & $\sim 90$ & $34 \cdot 65$ & 0 \\
\hline & RSD90-2 & $0 \cdot 633$ & $\sim 90$ & $34 \cdot 65$ & $0 \cdot 5$ \\
\hline & RED90-2 & $0 \cdot 645$ & $\sim 90$ & $34 \cdot 65$ & $1 \cdot 0$ \\
\hline \multirow[t]{3}{*}{ Series IV } & RCD90-3 & 0.633 & $\sim 90$ & 51.96 & 0 \\
\hline & RSD90-3 & 0.632 & $\sim 90$ & $51 \cdot 96$ & $0 \cdot 5$ \\
\hline & RED90-3 & $0 \cdot 633$ & $\sim 90$ & 51.96 & $1 \cdot 0$ \\
\hline
\end{tabular}

Table 3. Rotational shear tests conducted in this study

\footnotetext{
* Nominal values.
} 


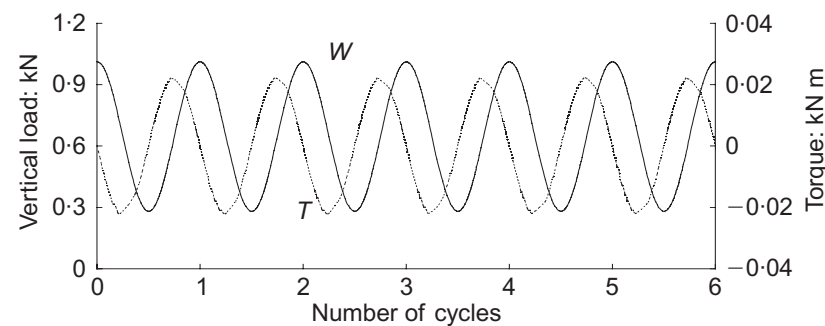

(a)

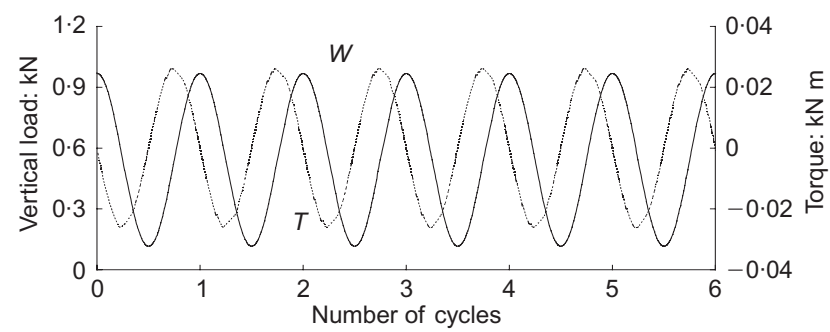

(b)

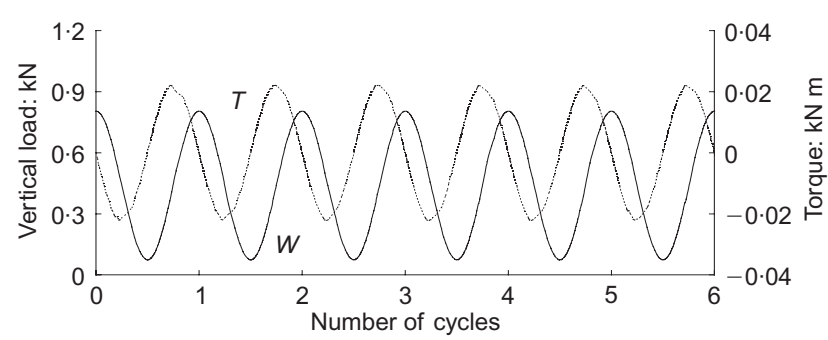

(c)

Fig. 5. Variation of vertical load and torque in rotational shear: (a) $b=0$; (b) $b=0.5$; (c) $b=1 \cdot 0$
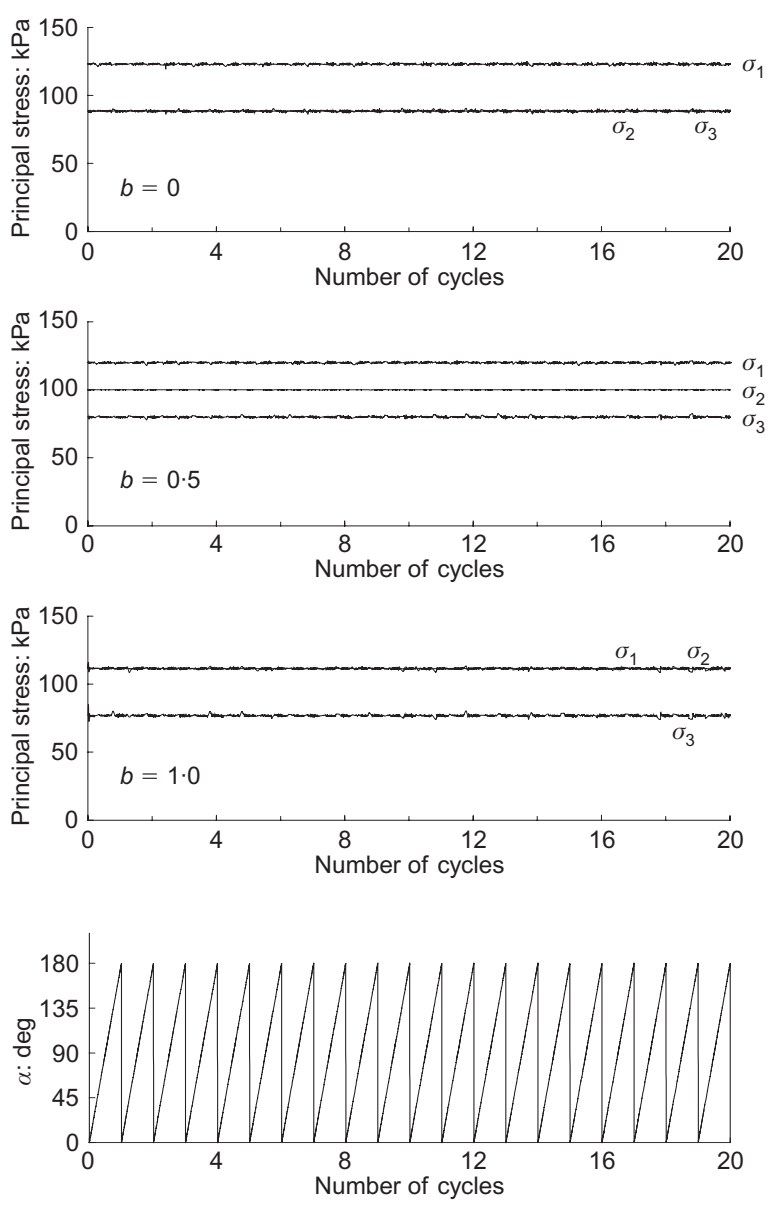

Fig. 6. Magnitude and direction of principal stresses
1990). It is found that the difference between the stresses determined using the radial average with those using the volumetric average is generally insignificant.

The shear stress $\sigma_{z \theta}$ can be obtained by taking the average

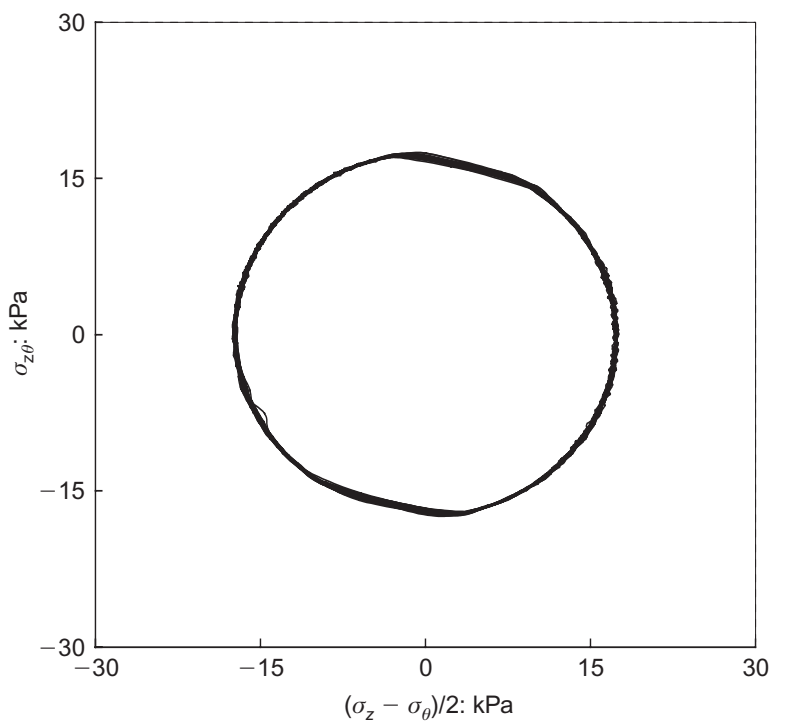

(a)

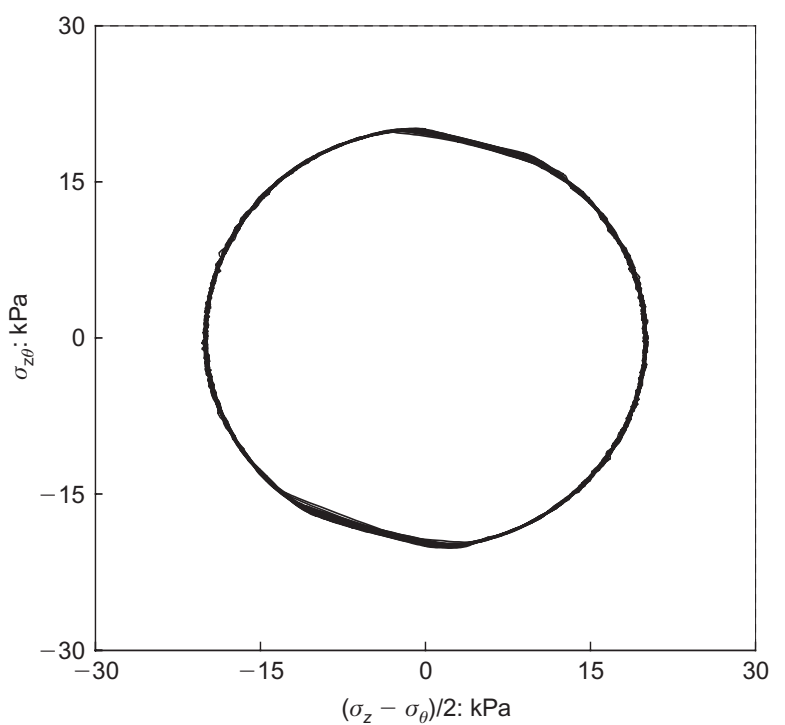

(b)

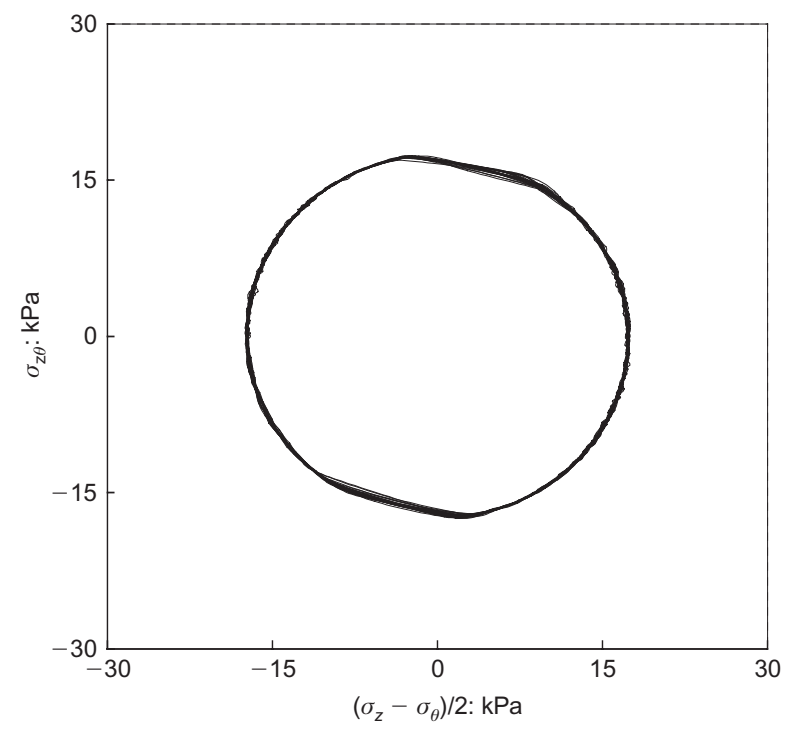

(c)

Fig. 7. Stress trajectory in $\sigma_{z} \theta-\left(\sigma_{z}-\sigma_{\theta}\right) / 2$ space for test series I: (a) $b=0$; (b) $b=0.5$; (c) $b=1.0$ 
value of the elastic and full plastic solutions for the shear stress in the hollow cylinder under torsional loading, as follows.

Elastic solution:

$$
\tau_{\mathrm{av}}^{\mathrm{e}}=\frac{4}{3 \pi} \frac{r_{\mathrm{o}}^{3}-r_{\mathrm{i}}^{3}}{\left(r_{\mathrm{o}}^{2}-r_{\mathrm{i}}^{2}\right)\left(r_{\mathrm{o}}^{4}-r_{\mathrm{i}}^{4}\right)} T
$$

Plastic solution:

$$
\begin{aligned}
\tau_{\mathrm{av}}^{\mathrm{p}} & =\frac{3}{2 \pi} \frac{1}{r_{\mathrm{o}}^{3}-r_{\mathrm{i}}^{3}} T \\
\sigma_{z \theta} & =\frac{1}{2}\left(\tau_{\mathrm{av}}^{\mathrm{e}}+\tau_{\mathrm{av}}^{\mathrm{p}}\right) \\
& =\frac{1}{2}\left[\frac{4}{3 \pi} \frac{r_{\mathrm{o}}^{3}-r_{\mathrm{i}}^{3}}{\left(r_{\mathrm{o}}^{2}-r_{\mathrm{i}}^{2}\right)\left(r_{\mathrm{o}}^{4}-r_{\mathrm{i}}^{4}\right)} T+\frac{3}{2 \pi} \frac{1}{r_{\mathrm{o}}^{3}-r_{\mathrm{i}}^{3}} T\right]
\end{aligned}
$$

In general, the stress and strain distributions in the hollow cylindrical specimens are not uniform, particularly when unequal inner and outer cell pressures are applied (Hight et al., 1983). The equations given in Table 2 represent only the average stress state. To reduce the non-uniformity, it has
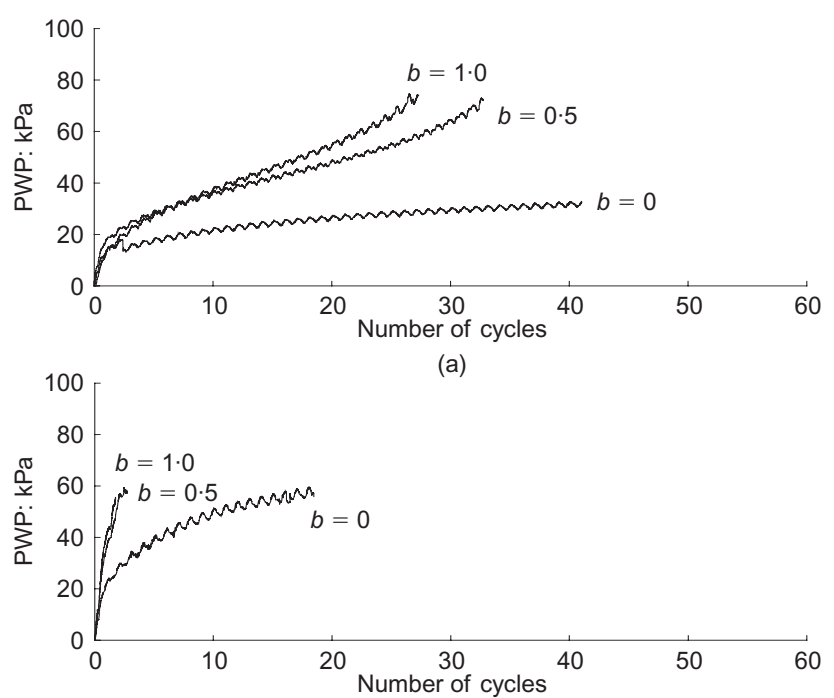

(b)

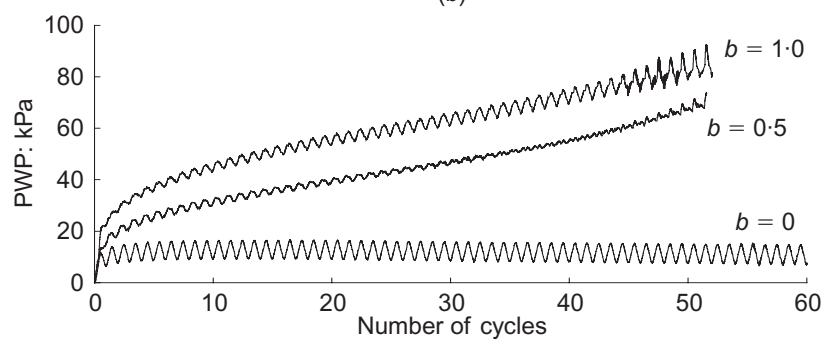

(c)

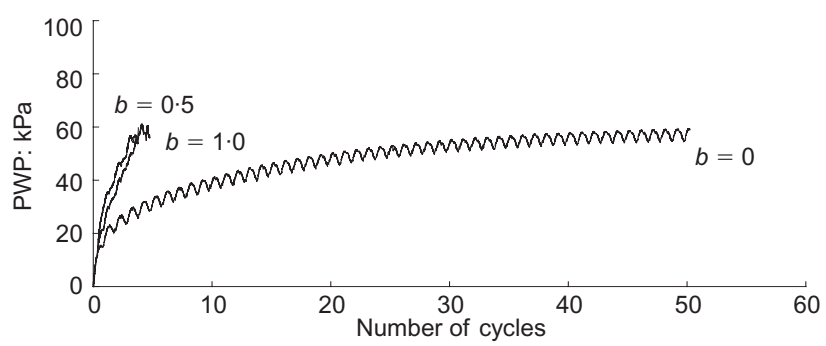

(d)

Fig. 8. Pore water pressures generated in rotational shear under various conditions: (a) $D_{\mathrm{r}}=70 \%, q=34.65 \mathrm{kPa}$; (b) $D_{\mathrm{r}}=70 \%$, $q=51.96 \mathrm{kPa}$; (c) $D_{\mathrm{r}}=90 \%, q=34.65 \mathrm{kPa}$; (d) $D_{\mathrm{r}}=90 \%$, $q=51.96 \mathrm{kPa}$ been suggested that the ratio between the outer and inner cell pressures should be limited to a range of $0.75<P_{0} / P_{\mathrm{i}}$ $<1.3$ (Gutierrez, 1989; Nakata et al., 1998). In the present study, this condition was well satisfied, and in this respect the non-uniformity is considered less significant.

\section{Test programme}

The programme for the rotational shear tests can be summarised as follows.

(a) The total principal stresses $\sigma_{1}, \sigma_{2}$ and $\sigma_{3}$ were kept constant while the directions of the principal stresses were continuously rotated in the physical space.

(b) The intermediate principal stress parameter $b$ and the deviatoric stress $q=\sqrt{3 J_{2 D}}=$ $\sqrt{\left[\left(\sigma_{1}-\sigma_{2}\right)^{2}+\left(\sigma_{2}-\sigma_{3}\right)^{2}+\left(\sigma_{3}-\sigma_{1}\right)^{2}\right] / 2}$ were maintained constant during rotation of the principal stresses.

In each test, the pressure cell was set up on the pedestal of the loading frame and a computerised initiation process was then followed. Inner and outer cell pressures of $30 \mathrm{kPa}$ were simultaneously applied. After checking the initial $B$ value, a back-pressure of $200 \mathrm{kPa}$ was applied to raise the degree of saturation of the soil specimen such that the $B$ value exceeded $0 \cdot 97$. Subsequently, anisotropic consolidation was performed, keeping the constant stress ratio to a desired stress state. The shearing stage was then commenced. Four independently controlled loads were simultaneously applied in an automatic manner. The torque was applied with an angular displacement rate of $0.1 \% \mathrm{~min}$, corresponding to a shear strain rate $\left(\dot{\gamma}=2 \dot{\varepsilon}_{z \theta}\right)$ of $0.05 \% / \mathrm{min}$, and the measured torque value was used to control the other three loads

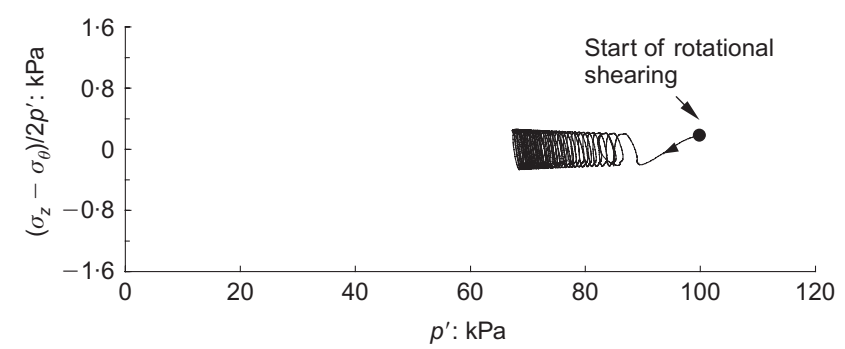

(a)

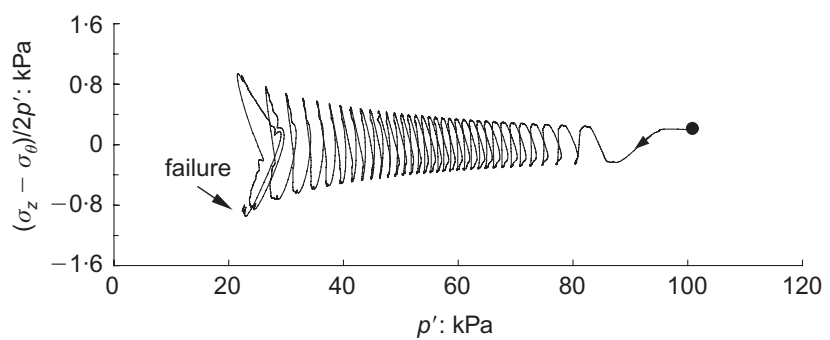

(b)

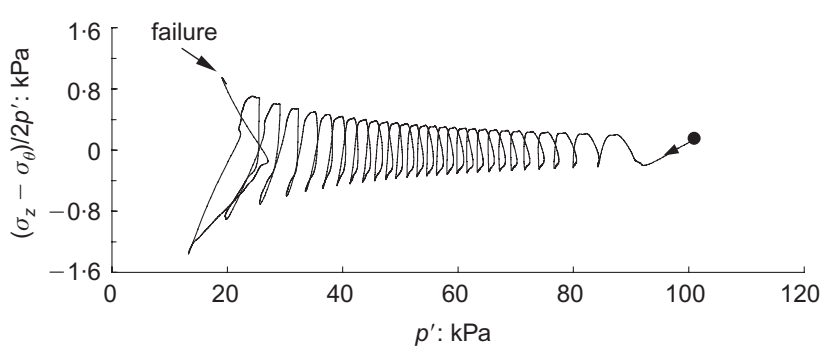

(c)

Fig. 9. Stress paths in $\left(\sigma_{z}-\sigma_{\theta}\right) 2 p^{\prime}-p^{\prime}$ space for test series I: (a) $b=0$; (b) $b=0.5$; (c) $b=0$ 
according to the prescribed rotational shearing path. The vertical displacement, the volume change in the inner chamber, the pore water pressure, the vertical load, the rotation angle, and the torque were measured and recorded during

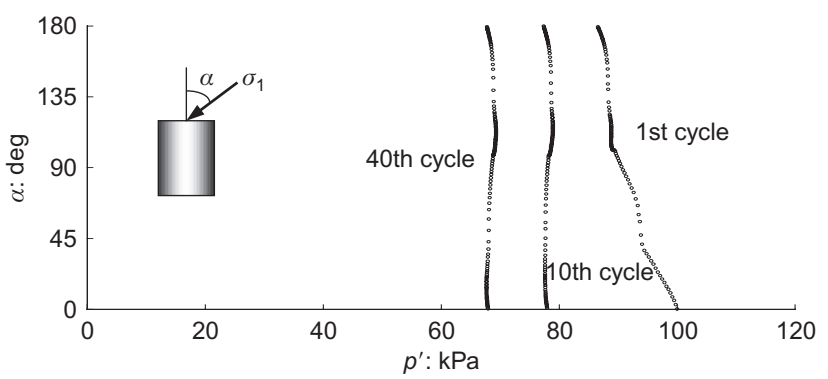

(a)

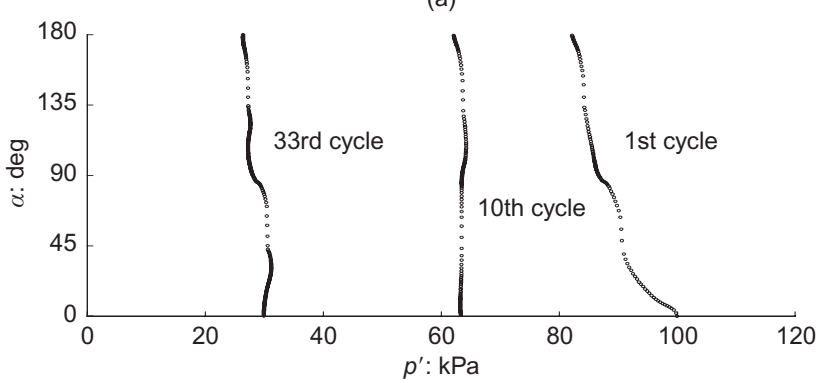

(b)

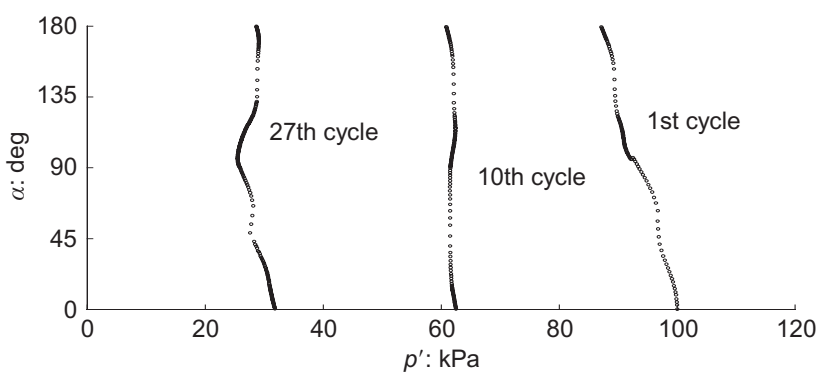

(c)

Fig. 10. Relations between $\alpha$ and $p^{\prime}$ for test series I: (a) $b=0$; (b) $b=0.5$; (c) $b=1 \cdot 0$ the test. Fig. 3 shows the deviatoric stress path in the $\sigma_{z \theta^{-}}$ $\left(\sigma_{z}-\sigma_{\theta}\right) / 2$ plane, where $\sigma_{z}$ is the axial stress.

A total of 12 undrained tests were conducted for various conditions. Two relative densities $\left(D_{\mathrm{r}}=70 \%\right.$ and $\left.90 \%\right)$, which represented the medium dense and very dense sand, were used in this study. According to the densities and applied deviatoric stress levels, all the tests were divided into four series, as listed in Table 3. Note that the initial void ratio $e_{0}$ and relative density $D_{\mathrm{r}}$ refer to values after the consolidation stage. All the tests were performed under the same initial mean normal stress of $p^{\prime}=100 \mathrm{kPa}$.

\section{TEST RESULTS AND DISCUSSION}

Variation of applied loads and stress components

Figure 4 shows the applied inner and outer cell pressures against the number of cycles of the stress rotation for test series I, in which the three plots represent three cases of the intermediate principal stress, that is, $b=0,0.5$ and 1.0 respectively. The variation of the applied vertical load and torque is shown in Fig. 5 for the same test series. It can be observed that, while the variation of the vertical load and torque had a similar pattern for all three values of $b$, the variation of the outer and inner cell pressures showed different patterns in terms of the amplitude and phase for different $b$ values. In each test the four loads were independently controlled so that the magnitude of the total principal stresses was maintained constant but the direction of the major principal stress, characterised by the angle $\alpha=$ $1 / 2 \arctan \left[2 \sigma_{z \theta} /\left(\sigma_{z}-\sigma_{\theta}\right)\right]$, was rotated continuously (Fig. $6)$. In each cycle of rotation $\alpha$ varied from $0^{\circ}$ to $180^{\circ}$. The stress trajectory plotted in the deviatoric stress plane $\sigma_{z \theta}-\left(\sigma_{z}\right.$ $\left.-\sigma_{\theta}\right) / 2$ was approximately a circle, as shown in Fig. 7.

\section{Evolution of pore water pressure in rotational shear}

Although the deviatoric stress $q=\sqrt{3 J_{2 D}}$ was maintained constant during each test, pore water pressure build-up due to rotation of the principal stress directions was consistently observed, even in very dense specimens, as shown in Fig. 8. For purposes of comparison, the results are grouped by test series into four plots in the figure. It is evident that the

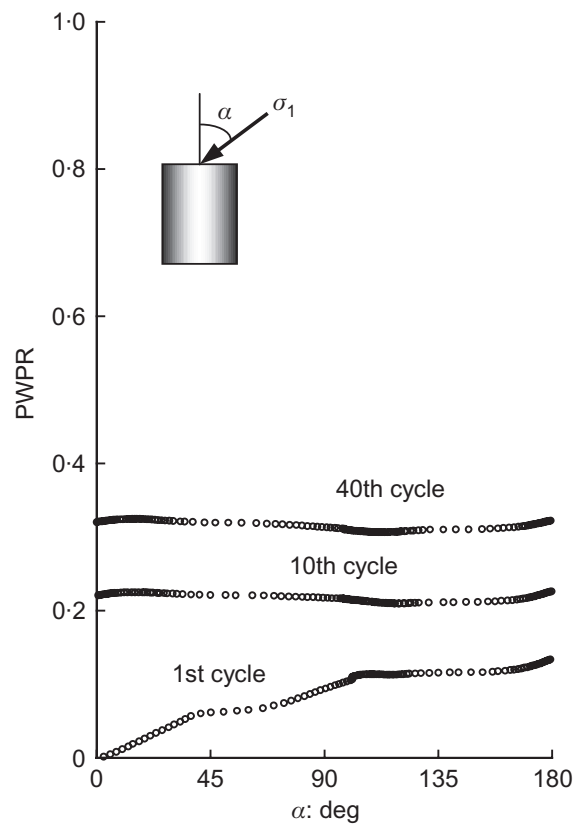

(a)

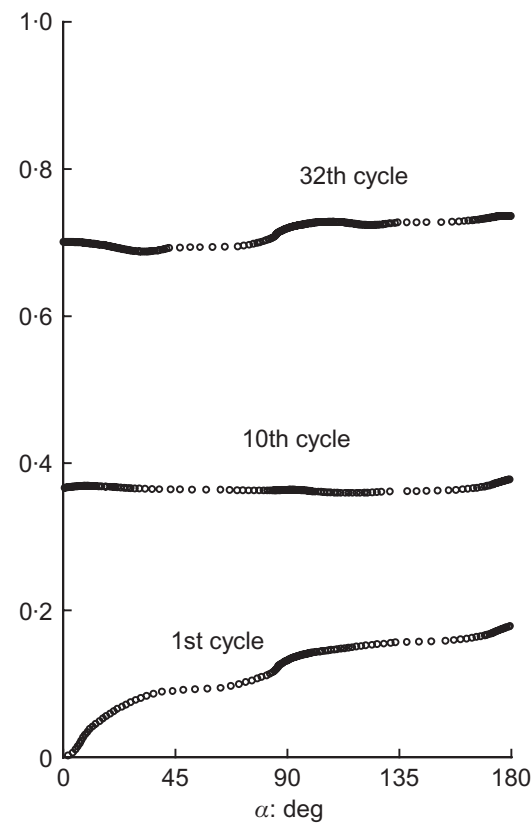

(b)

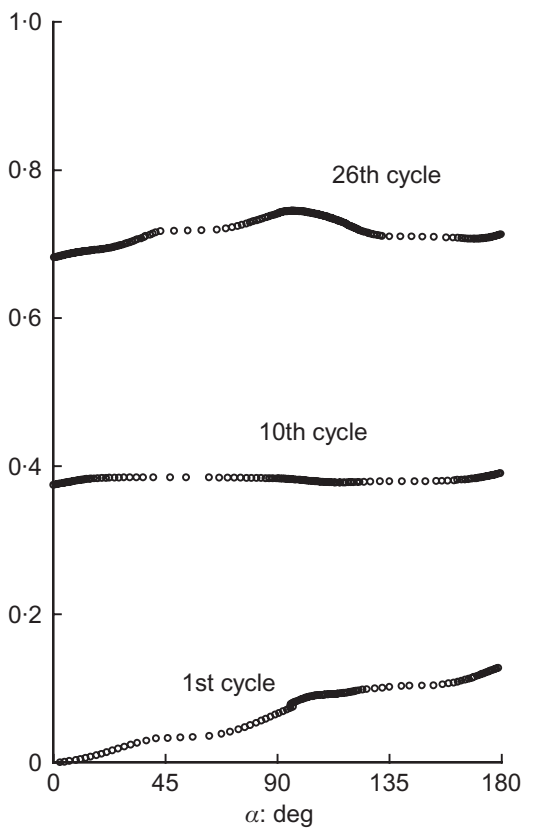

(c)

Fig. 11. Variation of pore water pressure ratio with $\alpha$ for test series I: (a) $b=0$; (b) $b=0 \cdot 5$; (c) $b=1 \cdot 0$ 


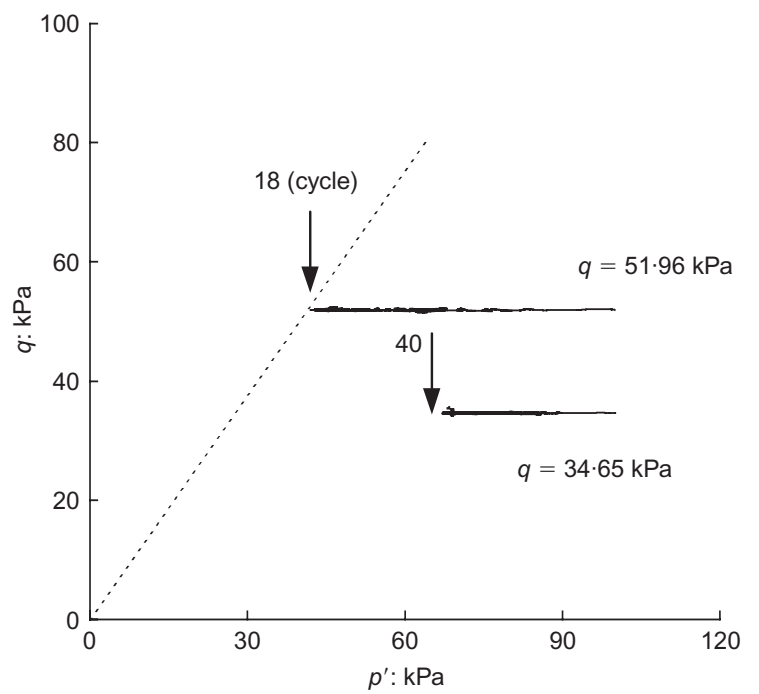

(a)

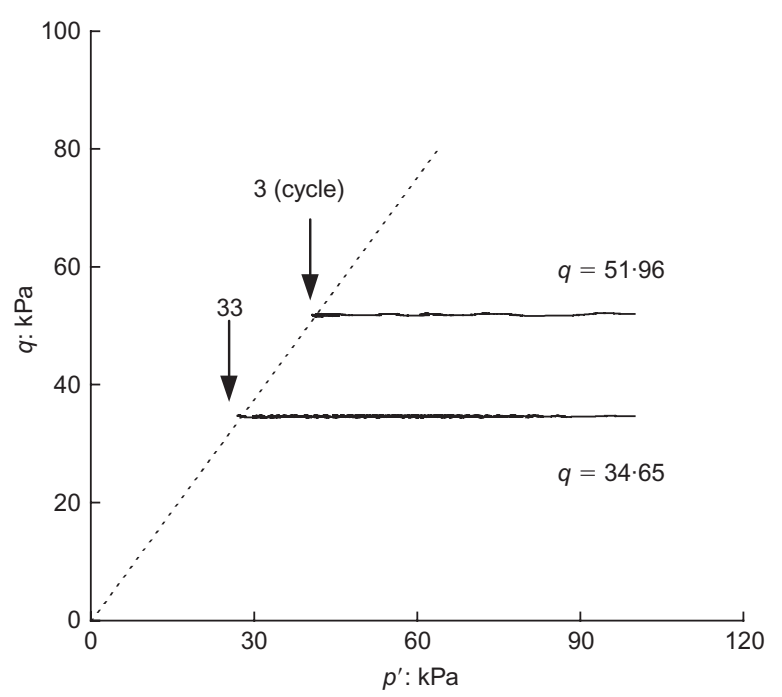

(c)

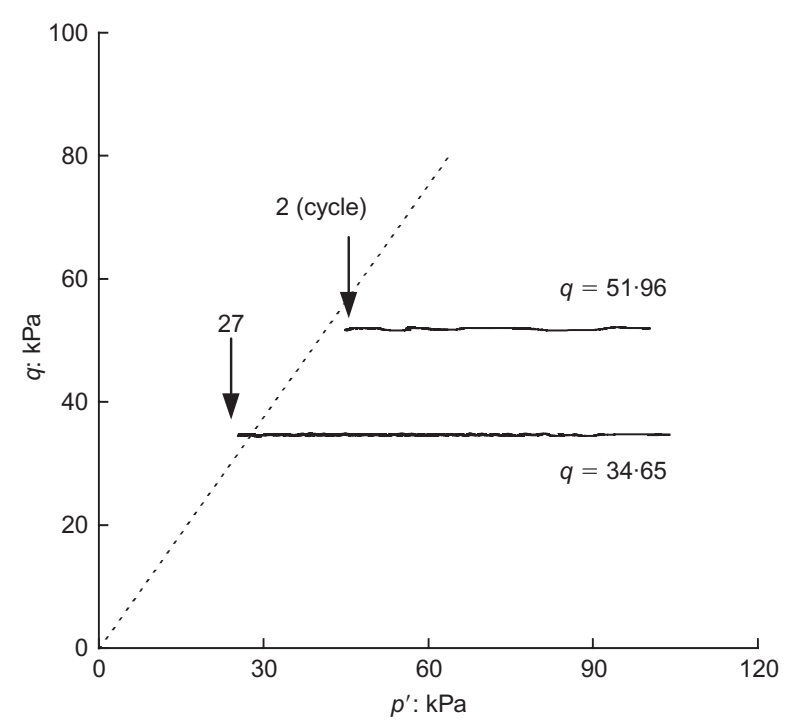

(e)

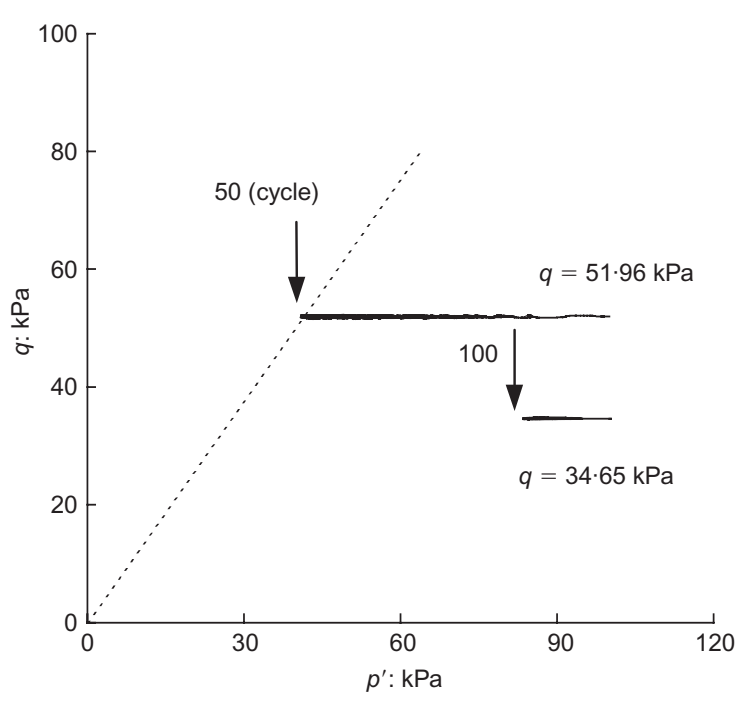

(b)

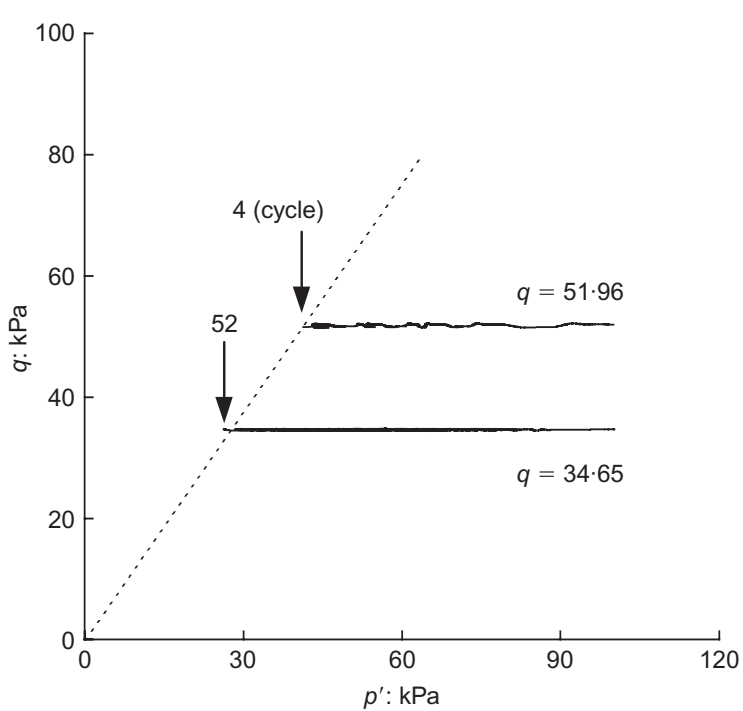

(d)

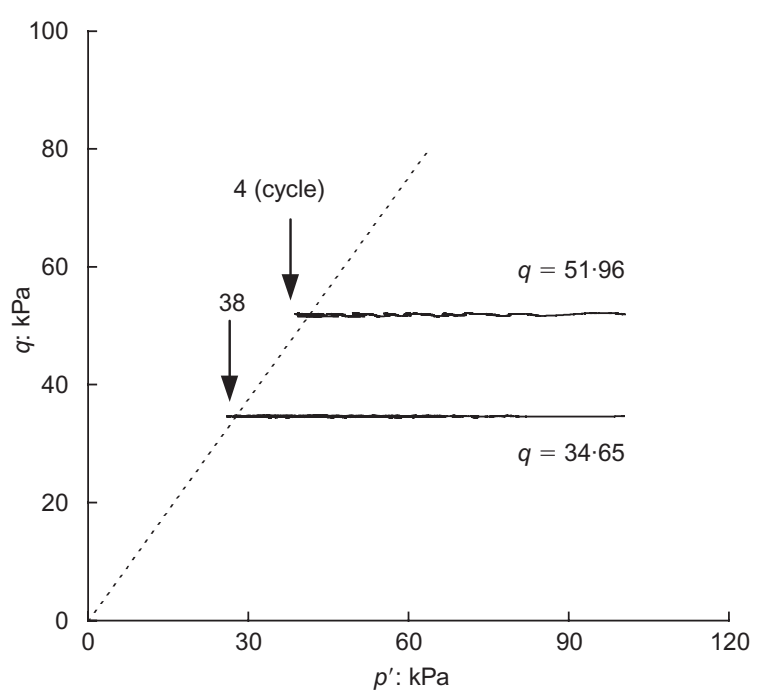

(f)

Fig. 12. Effective stress paths in $q-p^{\prime}$ space under various conditions: (a) $b=0, D_{\mathrm{r}}=70 \%$; (b) $b=0, D_{\mathrm{r}}=90 \%$; (c) $b=0 \cdot 5$, $D_{\mathrm{r}}=70 \%$; (d) $b=0.5, D_{\mathrm{r}}=90 \%$; (e) $b=1 \cdot 0, D_{\mathrm{r}}=70 \%$; (f) $b=1 \cdot 0, D_{\mathrm{r}}=90 \%$ 
pattern of pore water pressure generation was dependent on the value of $b$, the magnitude of the deviatoric stress $q$, and the initial density of the specimen $D_{\mathrm{r}}$. The rate of pore pressure generation under the condition $b=0$ was much slower than that under the conditions $b=0.5$ and $b=1 \cdot 0$, regardless of the soil density and the deviatoric stress magnitude. This observation suggests that the relative magnitude of the intermediate principal stress plays an important role in rotational shearing. This observation is in agreement with that observed in undrained shear tests conducted under the condition of fixed principal stress directions (Shibuya et al., 1984; Vaid \& Chern, 1985; Lam \& Tatsuoka, 1988).

Comparisons between Figs 8(a) and 8(b) and between Figs $8(\mathrm{c})$ and $8(\mathrm{~d})$ suggest that the effect due to the change of the deviatoric stress magnitude was also considerable: the larger the deviatoric stress applied, the faster the pore pressure rise. It is interesting to note that the difference in pore pressure response between the cases $b=0.5$ and $b=$ 1.0 tends to become smaller at the higher level of deviatoric stress. The specimen density was also found to have a significant influence on the pore pressure response. Under otherwise identical conditions, the pore pressure generally rose more rapidly in relatively loose samples. However, compared with the effect due to change in the magnitude of deviatoric stress, the influence of soil density appeared to be less pronounced in rotational shear.

Effective stress paths in different physical spaces

The evolution of the stress state and the variation of the effective mean normal stress, $p^{\prime}$, during the rotational shear for different $b$ values are of interest. Shown in Fig. 9 are the stress paths in $\left(\sigma_{z}-\sigma_{\theta}\right) / 2 p^{\prime}-p^{\prime}$ space for test series I. The three plots in the figure correspond to the three cases of $b$. It is clear that the influence of the intermediate principal stress had an important effect on the evolution of the stress state. The effective mean normal stress in the tests at $b=0.5$ and $b=1.0$ was reduced significantly, such that the soil specimens failed in both cases, whereas the specimen tested at $b$ $=0$ showed a limited reduction of the effective mean normal stress, and no sign of failure was observed.

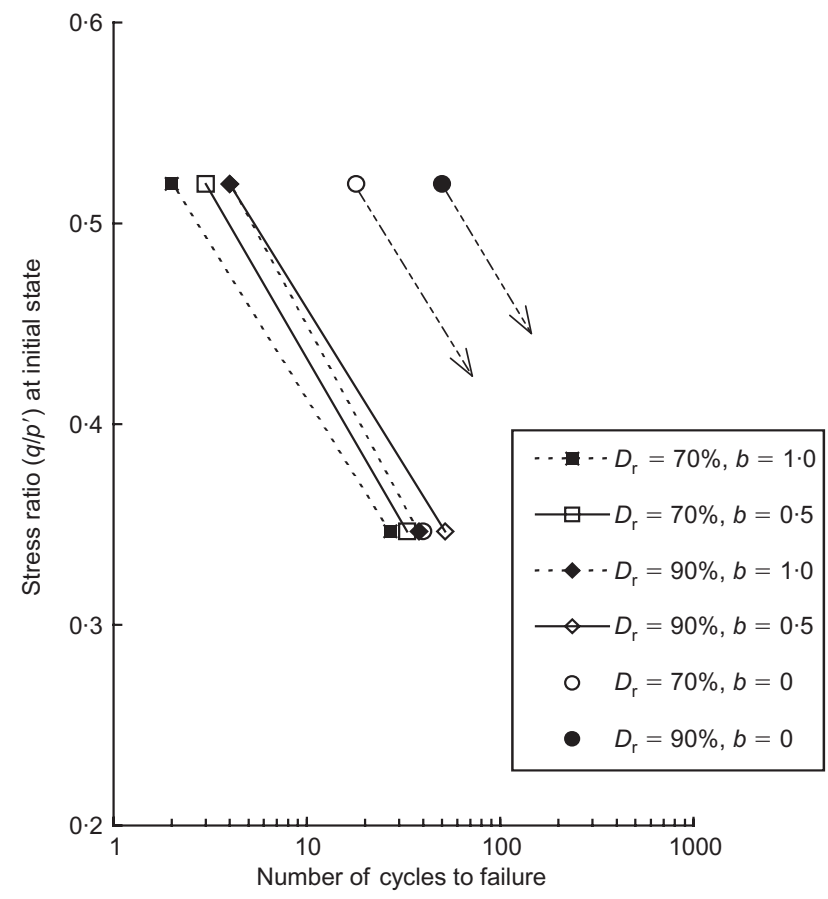

Fig. 13. Number of cycles required to failure
Figure 10 shows the change of the effective mean normal stress against the orientation of the major principal stress with reference to the vertical direction for test series I. This figure provides an alternative view of the effect of the $b$ value on the rate of pore pressure accumulation with increasing number of cycles. In the test conducted at the

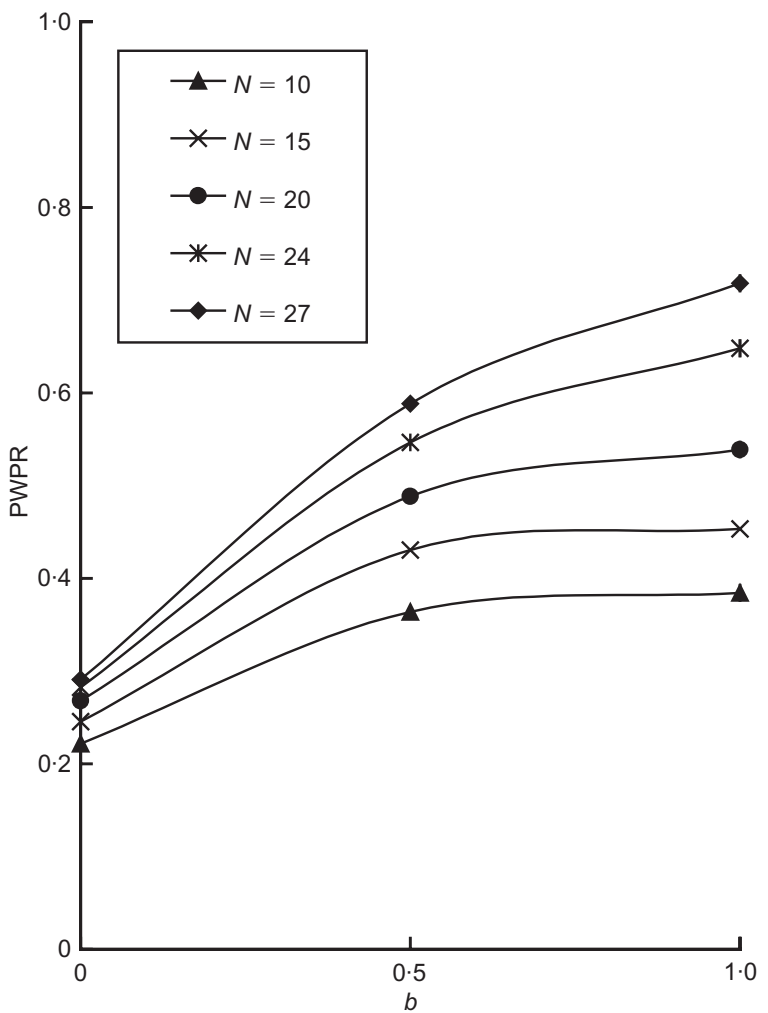

(a)

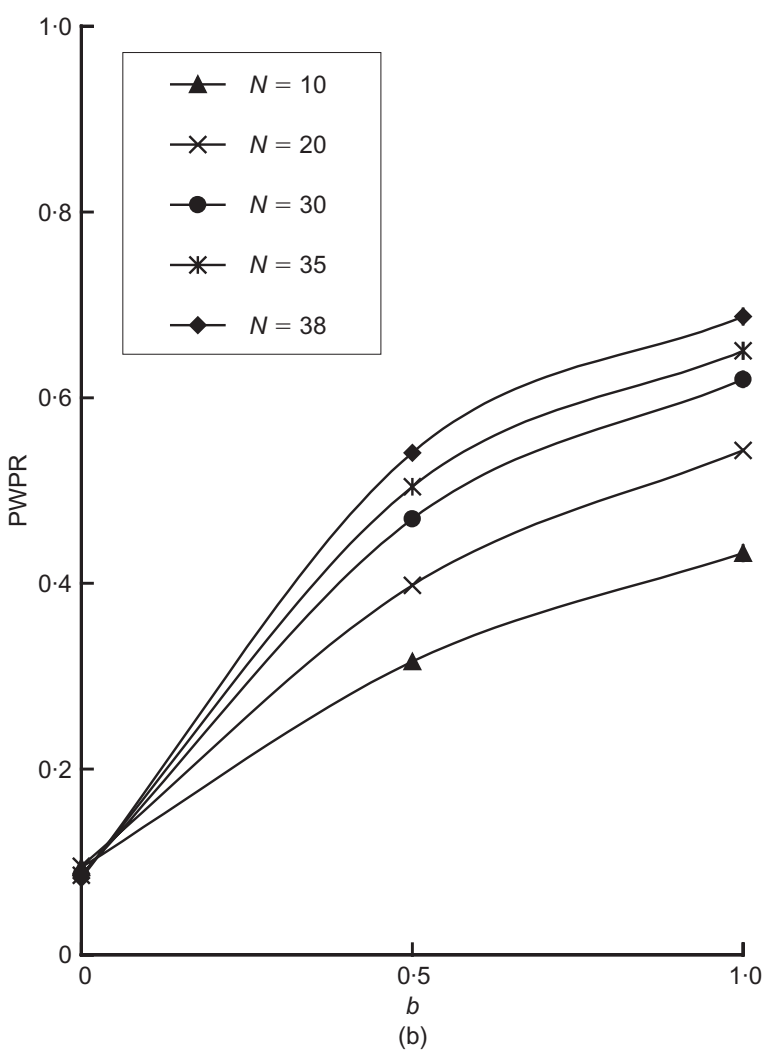

Fig. 14. Pore water pressure ratios at different numbers of cycles as a function of $b$ : (a) test series I; (b) test series III. $N=$ number of cycles of rotation 
condition $b=0$, the accumulation of pore pressure after 10 cycles of rotational shearing brought the effective mean normal stress to be about $80 \%$ of the initial mean normal stress, whereas in the tests under the conditions $b=0.5$ and 1.0 the effective mean normal stress after 10 cycles was

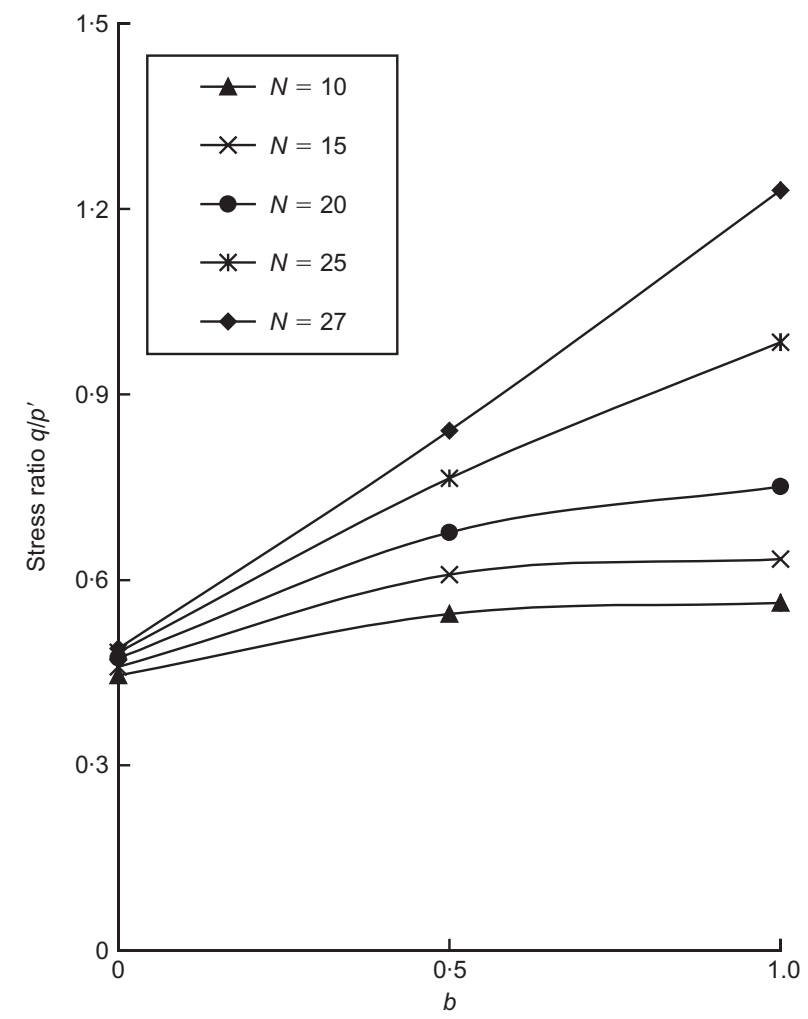

(a)

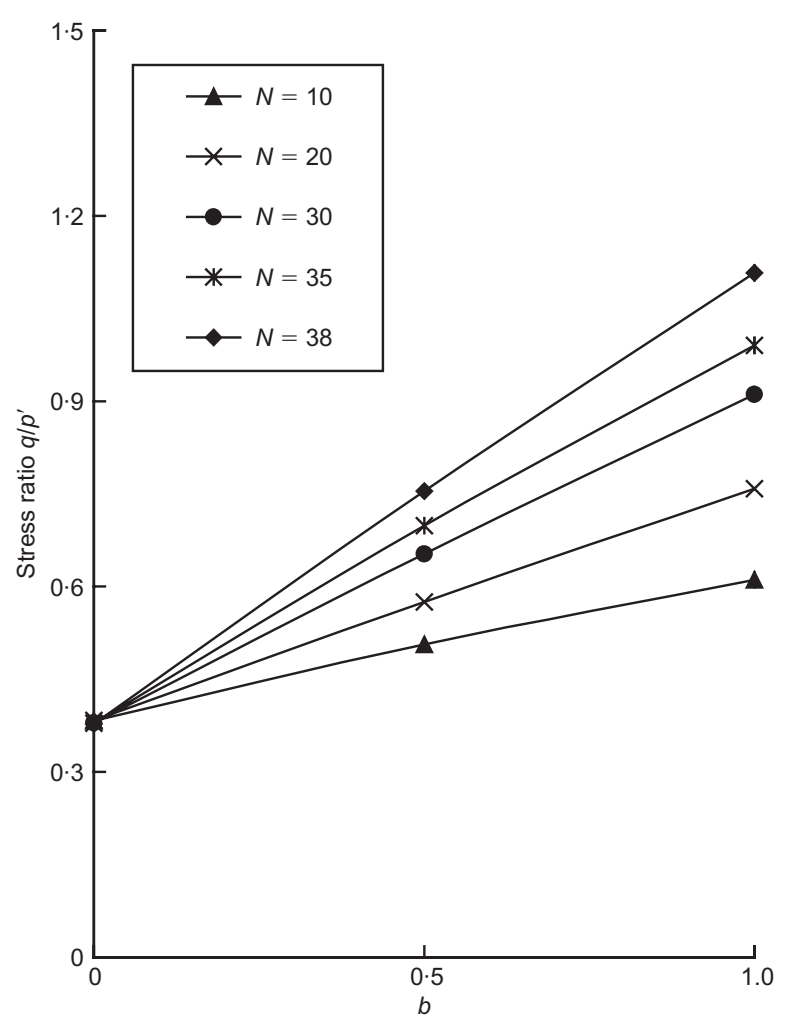

(b)

Fig. 15. Stress ratios $\left(q / p^{\prime}\right)$ at different numbers of cycles as a function of $b$ : (a) test series I; (b) test series III. $N=$ number of cycles of rotation reduced by $40 \%$. There is a phenomenon that is worth noting: for all three values of $b$, the reduction of the effective mean normal stress in the first cycle of rotation, that is, $\alpha$ varying from $0^{\circ}$ to $180^{\circ}$, appeared to be much more significant than that in any subsequent single cycle.

The pore water pressure ratio, PWPR, defined as the ratio between the pore water pressure and the initial mean effective stress, is a useful representation of the undrained strength. The variation of PWPR with rotation of principal stress is shown in Figs 11(a), 11(b) and 11(c) for the three values of $b$. It is clear that the soil specimen tested under the condition $b=0$ exhibited a stronger resistance to pore water pressure generation than that tested under the conditions $b=0.5$ and $b=1 \cdot 0$. For example, at the tenth cycle of rotation, the value of PWPR was approximately 0.22 at $b=0$, as compared with 0.37 at $b=0.5$ and $b=1.0$.

The effective stress paths in $q-p^{\prime}$ space are shown in Fig. 12 for all four series of tests. It is observed that, despite the density of the specimens, the effective mean normal stress was reduced all the way owing to the build-up of pore water pressure, leading the soil to failure. In most cases, when the stress ratio in terms of $q / p^{\prime}$ approaches 1.25 , the sample showed unstable response and the deformation increased abruptly. Fig. 12 indicates that the number of cycles of rotation required to reach failure was dependent on the $b$ value, the magnitude of the deviatoric stress, as well as on the specimen density. For example, for the specimen with density of $70 \%$ and subjected to deviatoric stress of $34.65 \mathrm{kPa}, 27$ cycles of rotation were required to bring it to failure under the condition $b=1 \cdot 0$, and 33 cycles were required under the condition $b=0 \cdot 5$. However, when the specimen was tested under the condition $b=0$, it showed no sign of failure even after 40 cycles of rotation.

It is also observed from Fig. 12 that, under otherwise identical conditions, the higher the deviatoric stress, the more likely the specimen is to lose effective stress, and the fewer the cycles required for failure. As far as the effect of

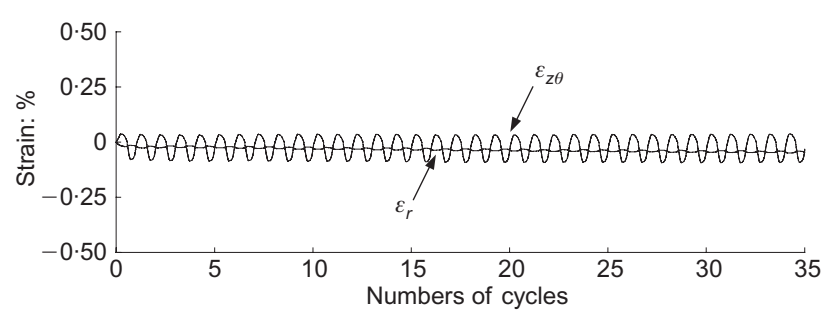

(a)

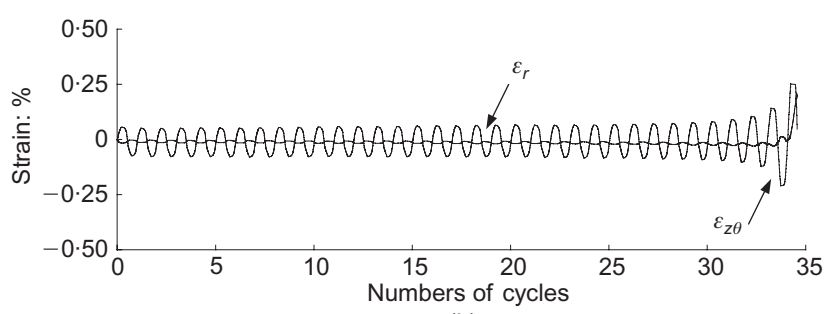

(b)

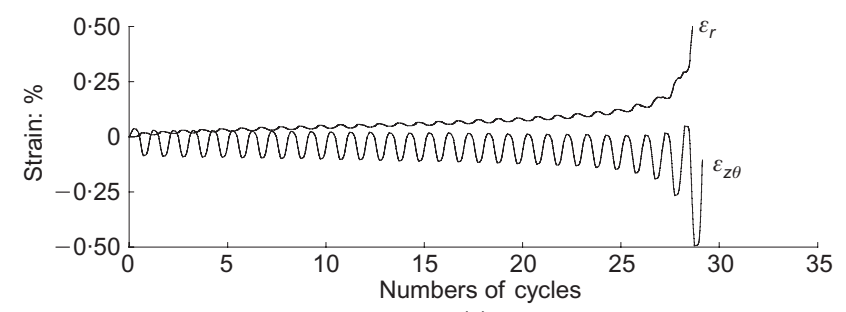

(c)

Fig. 16. Variation of strain components in rotational shear for test series I: (a) $b=0$; (b) $b=0.5$; (c) $b=1 \cdot 0$ 
soil density is concerned, the test results suggest that the denser the soil sample, the stronger is the resistance to the generation of pore water pressure. As a result, the number of cycles required approaching failure for the dense sample is greater than that for the loose one.

In Fig. 13 the initial stress ratio $q / p^{\prime}$ is shown against the number of cycles required approaching failure for various conditions. It can be seen that the case of $D_{\mathrm{r}}=70 \%$ and $b$ $=1.0$ was most prone to failure with the lowest resistance to the pore pressure build-up, whereas the case of $D_{\mathrm{r}}=90 \%$ and $b=0$ was the strongest in resisting the generation of pore water pressure and had the least possibility of failure in rotational shear. A different view of the effects of the intermediate principal stress on the undrained strength of the soil in rotational shear is presented in Figs 14 and 15, where the pore water pressure ratio and the stress ratio $q / p^{\prime}$ are assembled as a function of the $b$ value, respectively.

\section{Variation of strain components and strain paths}

As mentioned before, the sample at failure showed unstable response with an abrupt development of the deformation. A better view of this behaviour is provided by Figs 16 and 17. The former figure illustrates the strain components $\varepsilon_{r}$ and $\varepsilon_{z} \theta$ against the number of cycles of rotation for test series I. It is clear that, for the cases $b=0.5$ and $b=1.0$ where the soil samples failed, the magnitude of the two strain components suddenly increased at the onset of failure

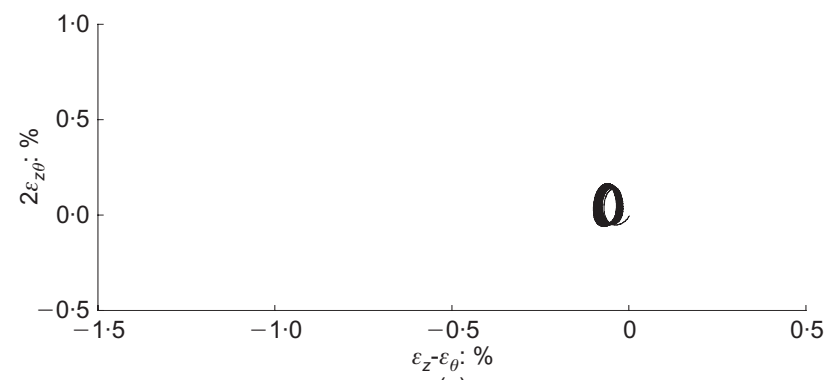

(a)

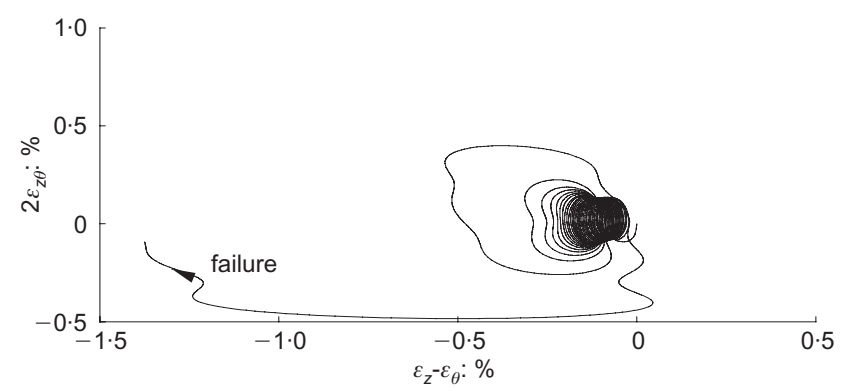

(b)

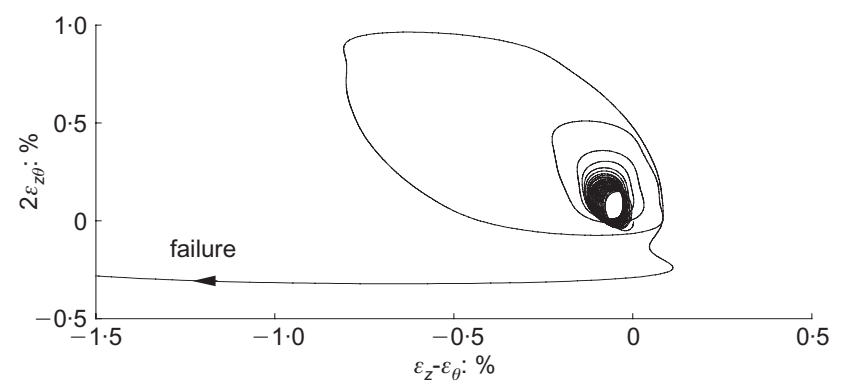

(c)

Fig. 17. Strain paths in deviatoric strain space for test series I: (a) $b=0$; (b) $b=0.5$; (c) $b=1.0$
(Figs 16(b) and 16(c)). The onset of failure occurred in the 33 rd cycle of rotational shearing for the case $b=0.5$ and in the 27 th cycle for the case $b=1 \cdot 0$. By comparison, the strain components in the case $b=0$ showed no sign of an abrupt development, with a steady oscillation during the entire course of the rotational shearing.

Figure 17 shows the strain paths in the deviatoric strain space $2 \varepsilon_{z \theta}-\left(\varepsilon_{z}-\varepsilon_{\theta}\right)$ for test series I. An enlarged view of the initial parts of the strain paths is given in Fig. 18. Clearly, the magnitude of strains accumulated with an increased number of cycles of rotation. For the rotational shear in the condition $b=0$, the strain paths were concentrated in a zone of very small deformation. A drastic development of deformation was observed in the other two tests conducted under otherwise identical conditions except that the $b$ value was different.

Shear stress-strain relationship in rotational shear

Figure 19(a) presents the shear stress-strain diagrams for test series I. While the magnitude of the deviatoric stress was maintained constant during the tests, the soil specimens showed hysteretic and plastic characteristics. It is to be noted that the intermediate principal stress played a significant role in the stress-strain relationship in rotational shear. The soil specimens sheared under the conditions $b=0.5$ and 1.0 showed a significant stiffness degradation when the specimens approached failure. Similar observations are shown in Fig. 19(b), where the shear stress-strain curves for test series II are given.

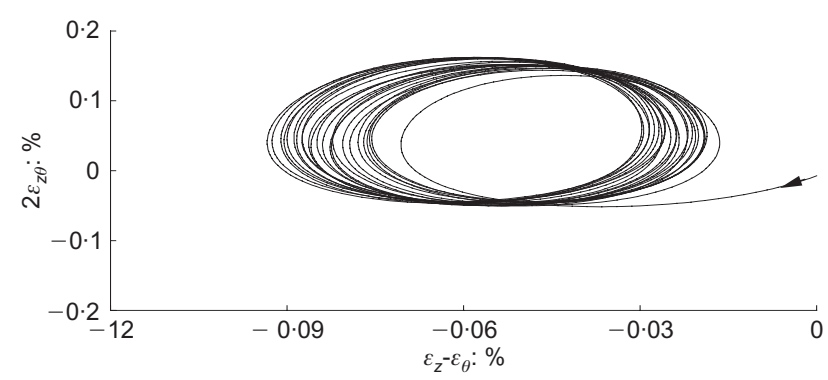

(a)

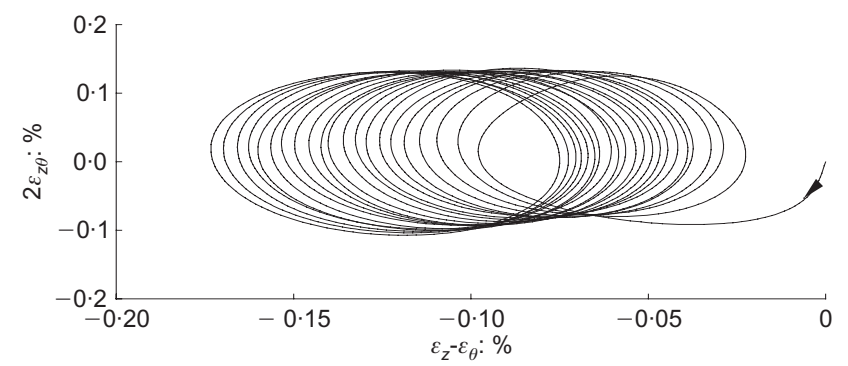

(b)

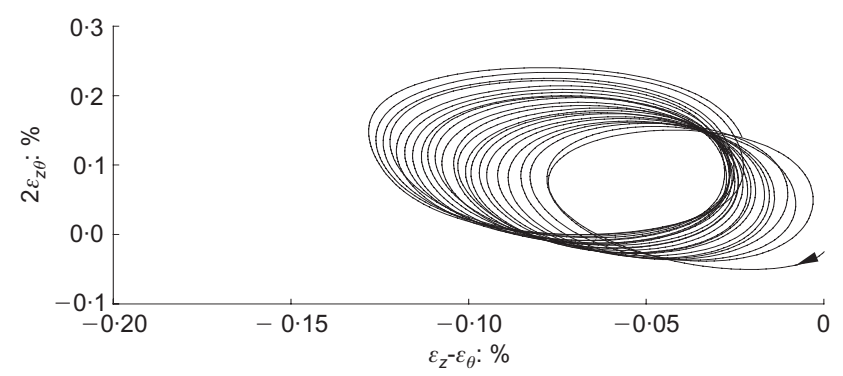

(c)

Fig. 18. Enlarged view of initial strain paths in deviatoric strain space for test series I: (a) $b=0$; (b) $b=0.5$; (c) $b=1 \cdot 0$ 

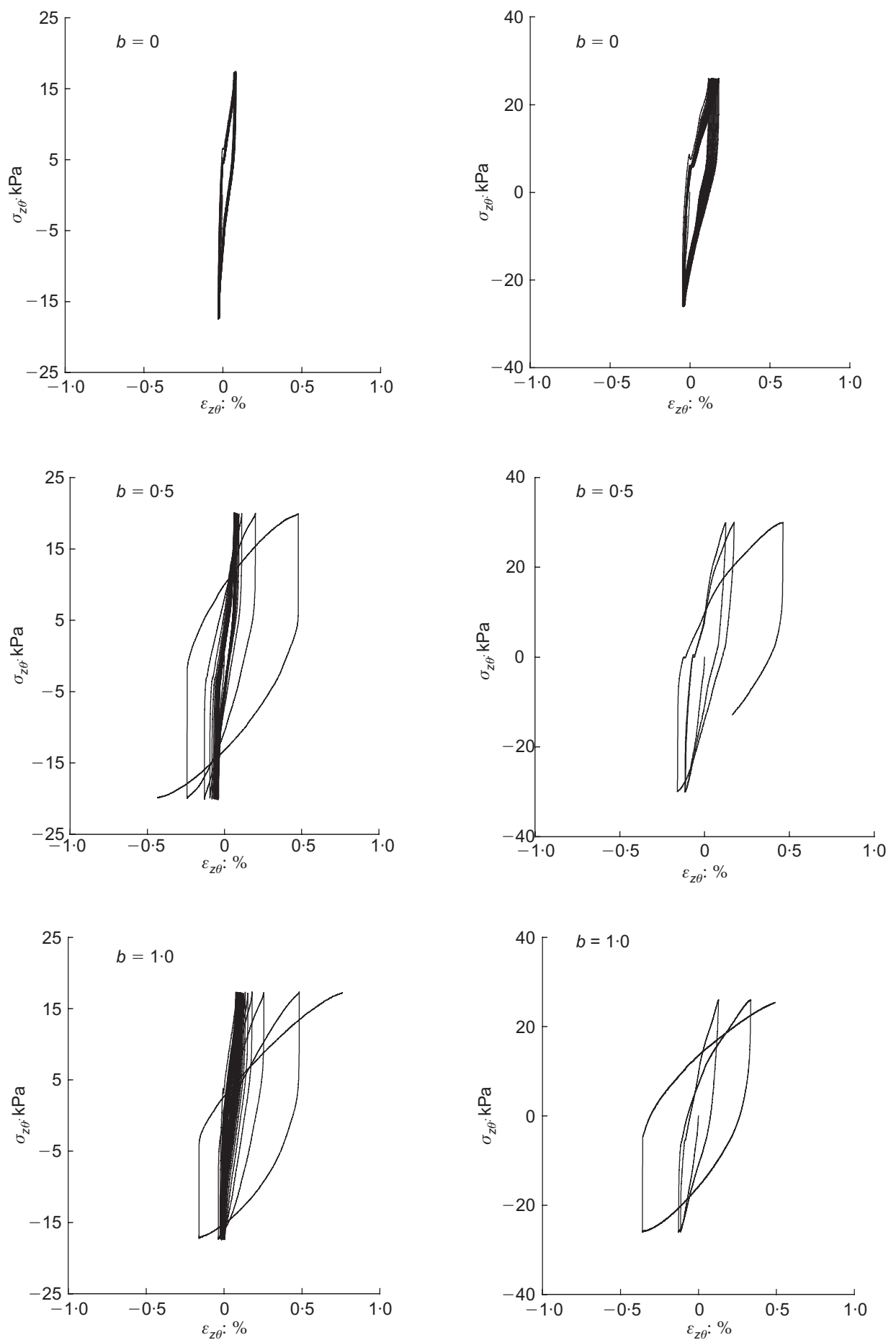

(a)

(b)

Fig. 19. Shear stress-strain relationship: (a) test series $I\left(D_{\mathrm{r}}=70 \%, q=34.65 \mathrm{kPa}\right)$; (b) test series II $\left(D_{\mathrm{r}}=70 \%, q=51.96 \mathrm{kPa}\right)$

To have a better view of the effect of the intermediate principal stress, the stiffness degradation is quantified and compared for all three values of $b$, as shown in Fig. 20. The stiffness degradation is simply represented by the ratio between the secant modulus in the $j$ th cycle of rotational shearing, $G_{j}$, and the secant modulus in the first cycle of rotation, $G_{1}$ (Fig. 20(a)). For test series I, which was conducted at $D_{\mathrm{r}}=70 \%$ and $q=34.65 \mathrm{kPa}$, a dramatic reduction of the shear modulus started in the 20th cycle of rotation in the cases of $b=0.5$ and 1.0 , with the modulus ratio being around 0.3 in the last cycle of rotation. By comparison, for the case $b=0$ the modulus experienced only a slight degradation in the first 20 cycles, with a modulus ratio of $0 \cdot 84$, and then remained approximately unchanged in subsequent cycles of rotational shearing. For test series II, which was conducted at the same density, $D_{\mathrm{r}}$ $=70 \%$, but at a higher level of $q, 51.96 \mathrm{kPa}$, the soil sample failed in the fourth cycle of rotation for $b=0.5$ and in the third cycle for of $b=1 \cdot 0$, with modulus ratio being less than $0 \cdot 2$. By comparison, the sample failed in the 18 th cycle with a modulus ratio of 0.62 for the case $b=0$.

\section{CONCLUSIONS}

This paper describes an experimental investigation into the anisotropic behaviour of saturated sand in undrained rotational shear using an automated hollow cylinder apparatus. The rotational shear is defined as a class of non- 


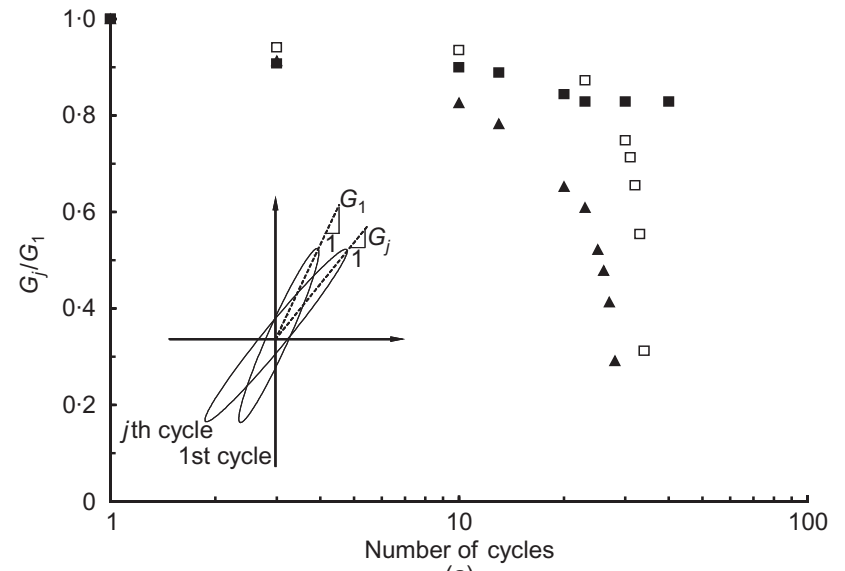

(a)

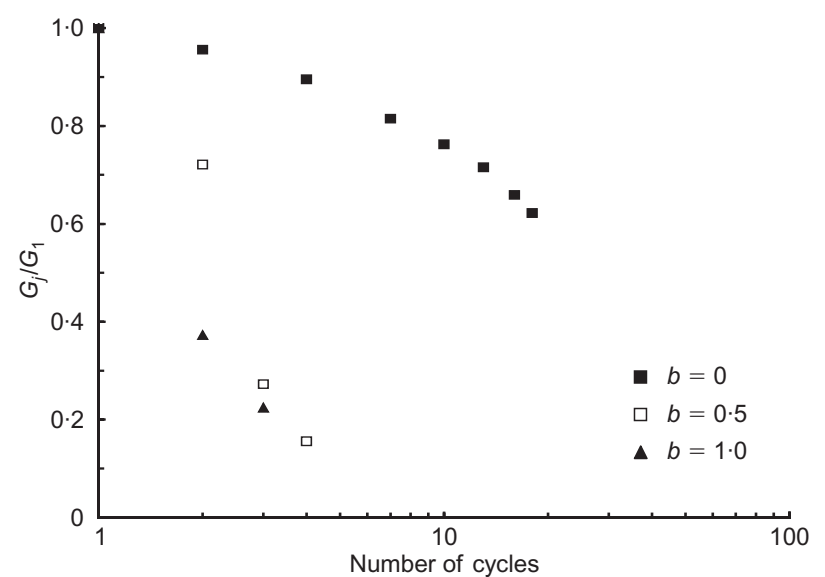

(b)

Fig. 20. Stiffness degradation for different $b$ values: (a) test series I $\left(D_{\mathrm{r}}=70 \%, q=34.65 \mathrm{kPa}\right)$; $(b)$ test series II $\left(D_{\mathrm{r}}=70 \%\right.$, $q=51.96 \mathrm{kPa})$

proportional loading in which the deviatoric stress remains constant while the principal stress directions are rotated continuously. Particular attention of the investigation has been placed on the influence of the intermediate principal stress in rotational shear. The major experimental observations and conclusions are summarised as follows.

(a) Soil specimens were weakened by the build-up of pore water pressure during rotational shearing under undrained conditions. The degree of weakening was dependent on the density of the specimen, the magnitude of the deviatoric stress and, particularly, the intermediate principal stress parameter $b$.

(b) The parameter $b$ was not a negligible factor for the pore pressure response during rotational shear, but had significant impact. The soil sheared under the condition $b=0$ generally showed a much stronger resistance to pore pressure build-up than the soil sheared under the conditions $b=0.5$ and $b=1.0$.

(c) While the deviatoric stress was maintained constant during rotational shearing, the shear stress-strain relationship showed hysteretic and plastic characteristics. The deformation characteristics in rotational shear were significantly affected by the parameter $b$. The stiffness degradation under the conditions $b=0.5$ and $b=1.0$ was more dramatic than that under the condition $b=0$.

(d) The magnitude of the deviatoric stress also had a significant effect on the pore pressure response and deformation characteristics during undrained rotational shear: the larger the deviatoric stress, the faster was the pore pressure build-up, and the more likely the soil was to fail.

(e) Under otherwise identical conditions, the pore pressure was generated more rapidly in relatively loose samples. However, compared with the effect due to the change of the deviatoric stress magnitude, the influence of the soil density appeared to be less pronounced in rotational shear.

$(f)$ As soil specimens may exhibit plastic deformation under the condition of constant deviatoric stress, conventional plasticity models are not able to predict the plastic deformation for the rotational shearing condition. New mechanisms need to be introduced into the constitutive models to account for the additional plastic deformation and fabric anisotropy.

\section{ACKNOWLEDGEMENTS}

The financial support provided by the Research Grants Council of Hong Kong (HKUST6002/02E and HKU7191/ $05 \mathrm{E})$ is gratefully acknowledged. The first author wishes to thank his former colleagues, Drs D. Su and Z. Y. Cai, for their help during the experimental work.

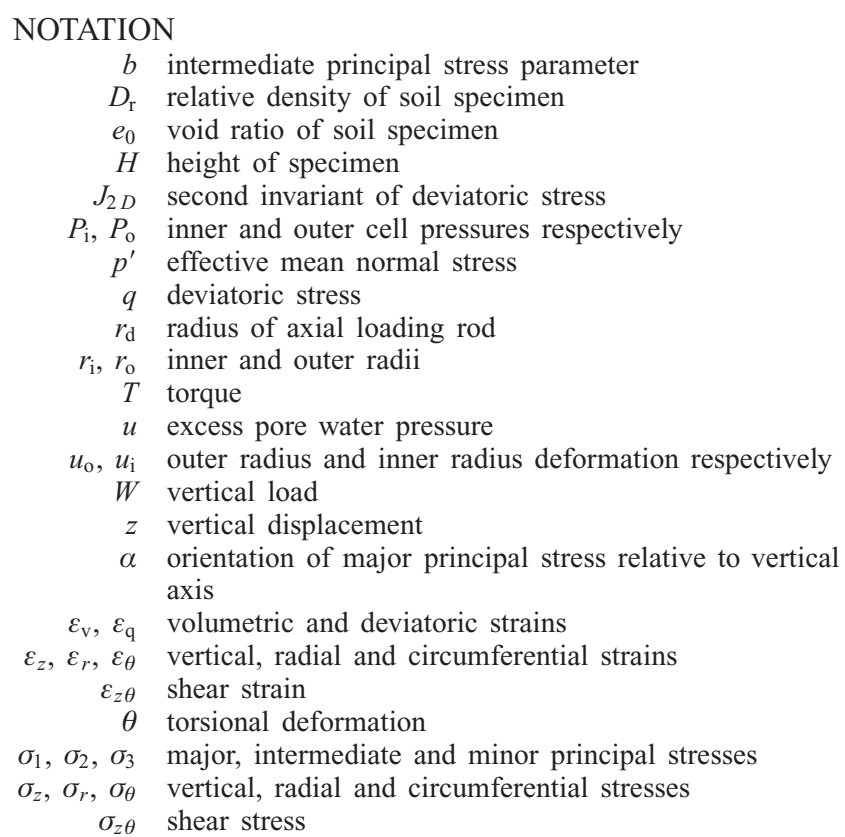

\section{REFERENCES}

Arthur, J. R. F. \& Menzies, B. (1972). Inherent anisotropy in a sand. Géotechnique 22, No. 1, 115-128.

Budiansky, B. (1959). A reassessment of deformation theories of plasticity. J. Appl. Mech., ASME 26, 259-264.

Finn, W. D. L. (2000). Post-liquefaction flow deformations. In Soil dynamics and liquefaction 2000, GSP 107, ASCE, pp. 108-122.

Gutierrez, M. (1989). Behavior of sand during rotation of principal stress directions. $\mathrm{PhD}$ thesis, University of Tokyo.

Hight, D. W., Gens, A. \& Symes, M. J. (1983). The development of a new hollow cylinder apparatus for investigating the effects of principal stress rotation in soils. Géotechnique 33, No. 4, $355-383$.

Ishihara, K. (1993). Liquefaction and flow failure during earthquakes. Géotechnique 43, No. 3, 351-415.

Ishihara, K. \& Towhata, I. (1983). Sand response to cyclic rotation of principal stress directions as induced by wave loads. Soils Found. 23, No. 4, 11-26.

Lam, W. K. \& Tatsuoka, F. (1988). Effects of initial anisotropic 
fabric and $\sigma_{2}$ on strength and deformation characteristics of sand. Soils Found. 28, No. 1, 89-106.

Li, X. S. \& Dafalias, Y. F. (2004). A constitutive framework for anisotropic sand including non-proportional loading. Géotechnique 54, No. 1, 41-55.

Miura, K., Miura, S. \& Toki, S. (1986). Deformation behavior of anisotropic dense sand under principal stress axes rotation. Soils Found. 26, No. 1, 36-52.

Nakata, Y., Hyodo, M., Murata, H. \& Yasufuku, N. (1998). Flow deformation of sands subjected to principal stress rotation. Soils Found. 38, No. 2, 115-128.

Oda, M. (1972). Initial fabrics and their relations to mechanical properties of granular materials. Soils Found. 12, No. 1, 17-36.

Riemer, M. F. \& Seed, R. B. (1997). Factors affecting the apparent position of steady state line. J. Geotech. Geoenviron. Engng, ASCE 123, No. 3, 281-288.

Shibuya, S., Hight, D. W. \& Symes, M. J. (1984). Discussion on the paper by Ishihara and Towhata (1983). Soils Found. 24, No. 3, $107-110$.

Symes, M. J., Gens, A. \& Hight, D. W. (1984). Undrained aniso- tropy and principal stress rotation in saturated sand. Géotechnique 34, No. 1, 11-27.

Vaid, Y. P. \& Chern, J. C. (1985). Cyclic and monotonic undrained response of saturated sands. Advances in the Art of Testing Soils under Cyclic Loading, ASCE National Convention, Detroit, $120-147$.

Vaid, Y. P., Sayao, A. \& Negussey, D. (1990). Generalized stresspath-dependent soil behaviour with a new hollow cylinder torsional apparatus. Can. Geotech. J. 27, No. 5, 601-616.

Vaid, Y. P. \& Sivathayalan, S. (1996). Static and cyclic liquefaction potential of Fraser Delta sand in simple shear and triaxial tests. Can. Geotech. J. 33, No. 2, 281-289.

Yang, J. (2002). Non-uniqueness of flow liquefaction line for loose sand. Géotechnique 52, No. 10, 757-760.

Yoshimine, M. \& Ishihara, K. (1998). Flow potential of sand during liquefaction. Soils Found. 38, No. 3, 189-198.

Yoshimine, M., Ishihara, K. \& Vargas, W. (1998). Effects of principal stress direction and intermediate principal stress on undrained shear behavior of sand. Soils Found. 38, No. 3, $179-188$. 